\title{
High intensity impact of granular matter with edge-clamped ductile plates
}

\author{
Anne Kyner, Kumar Dharmasena, Keith Williams*, Vikram Deshpande** and Haydn Wadley \\ Department of Materials Science and Engineering, University of Virginia, Charlottesville, Va \\ 22903, USA \\ * Newtec Services, Edgefield, SC \\ ** Engineering Department, Cambridge University, UK
}

\begin{abstract}
The deformation of ductile square stainless steel plates during central impact by high velocity, spherically symmetric granular particle shells has been investigated using an approach that combined large-scale experiments with numerical simulation. The study used suspended spherical explosive charges to accelerate 25 to $150 \mathrm{~kg}$ concentric shells of water saturated glass or higher density zirconia particles to velocities of $500-1200 \mathrm{~m} / \mathrm{s}$. The test charges were positioned above the center of $2.54 \mathrm{~cm}$ thick, $1.32 \mathrm{~m}$ x $1.32 \mathrm{~m}$ wide edge clamped panels made of 304 stainless steel, and their permanent deflection fields measured after testing. A novel edge restraint approach was utilized to avoid disruption of reflected particle flow over the impacted surface of the sample and so avoid plate failure near the gripped regions. The end of a Kolsky bar was positioned at a location symmetrically equivalent to the plate center, and was used to measure both the pressure and the specific impulse applied to the plate center. The evolution of the granular shell topology following charge detonation was characterized by analysis of high-speed video images. The radial expansion of the granular shells, the pressure and impulse that they transferred to the Kolsky bar, and the test plates out of plane displacement field were all well predicted by a discrete particlebased simulation approach. The study confirms earlier simplified model estimates of an approximately linear dependence of the plates out of plane displacement upon incident impulse, and validates the use of the edge restraint concept. It also experimentally identifies the existence of a granular shell velocity dependent instability at the leading edge of the fastest expanding granular shells.
\end{abstract}

Key words: Impulsive loading, granular matter, numerical simulation Communicating Author: Haydn Wadley 


\section{Introduction}

The acceleration of granular media by rapidly expanding gases and their subsequent impulsive loading of structures is a problem of significant scientific and technological research interest [13]. Both Pelean and Plinian volcanic eruptions involve the rapid, sometimes supersonic expansion of compressed high temperature gases that accelerate solid and molten particles to high velocity $[4,5]$. The resulting particle plumes can reach sufficient velocities to overcome gravitational and air drag resistances to reach the upper atmosphere [6]. Likewise, the detonation of a shallow buried explosive results in expanding detonation product gases that accelerate a substantial mass of soil particles to speeds in excess of $1000 \mathrm{~m} / \mathrm{s}$ [7]. While air drag can eventually slow the particles [811], the impact of high momentum particle flows with nearby structures can result in the application of significant pressures and momentum transfer, causing structural deformation or failure [12-15]. The mechanisms by which a rapidly expanding gas transfers momentum to granular media, the processes that slow or disperse the particles during propagation through the air, and those by which the structure subsequently responds to granular impact are therefore areas of considerable research interest [15-18].

The transfer of specific impulse (momentum per unit area) by granular media to structures has been both experimentally and numerically investigated in a series of sand slug impact investigations [19-21]. Figure 1 shows the numerically computed dimensionless out of plane maximum transient displacement, $\delta_{\max }$, of an edge clamped plate of span length $2 \mathrm{~L}$, following the impact of a sand slug with incident specific impulse, $I_{o}$, at an incidence angle of $90^{\circ}$ [19]. In this scenario, the sand particles were of uniform incident velocity. They did not appreciably bounce from the surface but instead flowed, like a laminar wall jet laterally across the surface after impact $[19,22]$. The transferred specific impulse was therefore approximately equal to the incident momentum per unit area of the sand slug. The dimensionless impulse, $\overline{I_{o}}=I_{o} / m_{b} \sqrt{\sigma_{Y} / \rho_{m}}$, shown in Figure 1, is the specific impulse divided by the mass per unit area of the plate, $m_{b}=\rho_{m} h$, and the plastic wave speed of the plate, $\left(\sigma_{\mathrm{y}} / \rho_{\mathrm{m}}\right)^{1 / 2}$, where $\sigma_{\mathrm{y}}$ is the plate's yield strength and $\rho_{\mathrm{m}}$ its density. This dimensionless analysis indicates that the out of plane displacement is an approximately linear function of specific impulse for impacts by particles at normal incidence, but can be reduced by use of high strength plate materials of low density [19]. 
In the problems of interest here, the granular particles suffer differential accelerations and are subject to different velocity dependent air drag forces during propagation [8-11]. They therefore possess a distribution of impact velocities and angles of incidence upon impact with a planar structure. Since the momentum transferred by each particle impact is a function of the particle mass, speed, and its angle of incidence, and depends upon the mass and local velocity of the surface being impacted, prediction of the impulse can be complicated. For example, late arriving granular impacts with an already deforming plate surface no longer encounter a flat or stationary surface, and the impulse transferred to the plate can differ from that during early stage impacts. These granular particle-structure interactions $[12,23]$ result in effects akin to Taylor's fluid structure interaction (FSI) $[24,25]$, and the time-dependent loads that cause plate deformation can be difficult to estimate. The manner in which a test structure is supported (especially the end gripping conditions) further complicate the displacement response of the structure. During high intensity impulsive loading, rigidly edge clamped panels are susceptible to pull-in, and to plate failure at the grips by shear localization or necking $[14,26,27]$. The edge effects can be severe, especially when the grips extend above the impacted surface of the plate since this causes outward reflection of the granular wall jet with an associated (inward) reaction momentum that promotes shear failure $[12,26]$.

Recently, Kyner et al. [11] developed a granular impact test method based upon a suspended spherical charge that radially accelerated a thick shell of water saturated silica (glass) particles toward the center of an edge clamped test plate. The plate was edge gripped in a manner that avoided grip induced outward reflection of the particles that flowed across the plate surface, thereby avoiding the shear-off process. Acceleration of the particles to a velocity of $\sim 1200 \mathrm{~m} / \mathrm{s}$ was observed using high-speed video techniques, and the pressure and impulse incident upon the plate center was measured using a Kolsky bar [28-30] (in the manner originally proposed by Hopkinson [31]) placed at a symmetrically equivalent location to the spherically expanding particles. It identified the presence of a sand "finger" instability at the sand front's leading edge where the sand speed was as much as $30 \%$ higher than the main sand front. The study also showed that a particle-based numerical simulation method implemented in the IMPETUS Afea Solver [3234] successfully modelled the detonation of a high explosive and the transfer of momentum from the detonation products to a granular medium. It successfully modelled the acceleration of the particles to a peak velocity, their interaction with air including the development of a high-pressure 
air shock ahead of the sand, and indicated the presence of locally faster sand particles. It successfully modelled their impact with a Kolsky bar and predicted the applied pressure and impulse, as well as that applied to a stainless steel plate, and the plate's subsequent dynamic deformation [11].

While the particle-based simulation approach has produced similarly encouraging results for lower intensity loading scenarios, its scalability to higher intensity loading situations has not been investigated. Its utility for modeling other granular materials with a different density, elastic stiffness and shape from spherical glass particles (silica) has also not yet been established. The study reported here extends the earlier study of Kyner et al. [11] to investigate the effects of increasing the impulsive loads applied by water saturated granular media. It conducts a set of tests in which glass particles were replaced by much denser zirconia particles, creating higher impulse loading conditions but with a substantially lower velocity impact. The series of tests also varies the ratio of granular material to explosive charge mass to investigate its effect upon the applied pressure and impulse transferred to the test samples. High-speed video imaging is used to observe the sand propagation, and to measure the granular particle front velocities. An instrumented Kolsky bar was again used to measure the applied pressure and impulse loading by the accelerated granular media. Simulations implemented via the IMPETUS Afea Solver were compared with the Kolsky bar measurements and plate deformation mapping to ascertain the validity of the simulations. They were then used to analyze the sand front movement and mechanisms of particle interaction with the test plate for tests that applied specific impulses up to $25 \mathrm{kPa} \cdot \mathrm{s}$.

\section{Experimental Setup}

To investigate the deformation of structures under very high intensity granular media loading conditions, a five shot experimental test series was conducted at an outdoor blast testing facility (NEWTEC Services Group, Inc. in Edgefield, SC) using large edge clamped plates made from a high ductility 304 stainless steel. Three of the tests enabled exploration of the effects of changing the mass of water saturated fused silica particles to that of the explosive driver. The two additional tests used a higher mass of water saturated zirconia particles, and enabled the consequences of changing the density of the particles to be assessed. 


\subsection{Test platform}

A schematic illustration of the test arrangement is shown in Figure 2. It is similar to that described by Kyner et al. [11], but used a more heavily reinforced support base structure to avoid rupture of the supports during repeated testing. The test system consisted of; (i) a solid picture frame test platform to support the test plates, (ii) a suspended, spherical explosive charge encased by an annular shell of water saturated fused silica or zirconia particles, and (iii) a steel Kolsky bar instrumented with strain gauges to measure the applied pressure and impulse loading at a symmetrically equivalent location to the center of the test plate, Figure 2(b). The test plates were mounted on two A-36 steel, square picture frame support plates with an $81.3 \mathrm{~cm} \mathrm{x} 81.3 \mathrm{~cm}$ square, center cutout, Figure 3. The upper most picture frame plate was $5.1 \mathrm{~cm}$ thick and was placed on a second $15 \mathrm{~cm}$ thick plate. This thicker support plate replaced a less robust I-beam used in the earlier study [11], which underwent permanent deformation and eventual fracture under the high intensity loading conditions like those used here. Steel stock shim pieces were used as necessary to fill any small gaps between the test plates and the picture frame support plate to which the test plates were secured, Figure 3. The plate span, 2L, between the edge clamps (where inplane plate stretching occurred) was $1.22 \mathrm{~m}$ while that where out-of-plane panel bending was permitted was $81.3 \mathrm{~cm}$ (defined by the center cutout of the picture frame steel supports), Figure 3.

A 3D view of the test arrangement with the reinforced support plate is shown in Figure 2(a). Both picture frame plates had four corner bolt-holes that aligned with holes in the test plate corners to secure the test plate to the support base using $1.9 \mathrm{~cm}$ diameter, Grade 8 bolts. The steel picture frame support structure was mounted on a wooden frame placed above cinder blocks that raised the platform to an optimal height for visual observation of the tests. To reduce structural damage to the test structure, a $0.95 \mathrm{~cm}$ thick rubber mat was placed between the steel support plates and the wooden structural frame.

A pair of Vision Research Inc., Phantom V7.3 high-speed cameras were used for observation of the test shots after detonation. These cameras were positioned side by side approximately $20 \mathrm{~m}$ in front of the test platform. One camera provided a wide view of the test event while the other provided a more magnified image of the test charge, test plate, and impact end of the Kolsky bar. The magnified image used a reduced number of pixels to allow the recording of more frames per second. The images from the high-speed video cameras were used to visualize and track the granular material front position during its propagation towards the Kolsky bar and test plate. The 
$1.32 \mathrm{~m}$ length front edge of the test plates was spray painted prior to each test shot to provide a length scale reference for the high-speed video calculations of sand front position and velocity. The front end of the Kolsky bar was also painted to provide a reference scale. The painted length was $10 \mathrm{~cm}$ for test Shots $1-3$ and $15 \mathrm{~cm}$ for Shots 4 and 5 . The optimum sampling rate of the highspeed videos varied from shot to shot due to variations in lighting. The data shown later used inter-frame times of 100, 111, 87, 48, and $29 \mu$ s for Shot 1 through Shot 5 respectively.

\subsection{Stainless steel targets}

Five, $2.54 \mathrm{~cm}$ thick, $1.32 \mathrm{~m} \times 1.32 \mathrm{~m} 304$ stainless steel plates were used for the study. The test plates were first annealed at $538^{\circ} \mathrm{C}$ for eight hours (Rex Heat Treat, Lansdale, PA) to remove internal stress and then machined to their square shape at KVK Precision Specialties Inc. (Shenandoah, VA). To resist the large pull-in forces at the periphery of the edge clamped test plate, four, $1.32 \mathrm{~m}$ length, $5.1 \mathrm{~cm}$ wide by $2.54 \mathrm{~cm}$ thick, rectangular 304 stainless steel bars were welded along the four edges of the underside of the test plates forming a frame on the (eventual) underside of the plates. These edge grips were then fitted over the A-36 steel support frame to provide effective edge restraint during impact loading while preventing local impulse amplification observed in studies where the edge grips extended above the top surface of the test plate $[12,26]$. As in the previous test [11], the edge grip welded attachment was reinforced using

high strength steel dowel pins that were press-fitted through a series of predrilled holes that penetrated the test plate and edge grips.

\subsection{Charge configurations}

A spherical Composition-4 (C4) explosive charge surrounded by a concentric granular media shell was suspended above the center of each test plate to provide impulse loading to the square 304 stainless steel test plates, Figure 3. To optimize investigation of the effect of impulse upon the test plate deflection, a series of simulations were first performed using the IMPETUS Afea particle based simulation code to identify appropriate explosive mass and granular shell thickness/density combinations. The five charge configurations developed using this approach are summarized in Table 1. 
Table 1. Charge configurations for the five test shots.

\begin{tabular}{lcccccccc}
\hline $\begin{array}{c}\text { Test } \\
\text { shot }\end{array}$ & $\begin{array}{c}\text { Inner } \\
\text { radius, } \\
\mathrm{R}_{1}(\mathrm{~mm})\end{array}$ & $\begin{array}{c}\text { Explosive } \\
\text { mass } \\
(\mathrm{kg})\end{array}$ & $\begin{array}{c}\text { Outer } \\
\text { radius, } \\
\mathrm{R}_{2}(\mathrm{~mm})\end{array}$ & $\begin{array}{c}\text { Annular } \\
\text { shell width } \\
(\mathrm{mm})\end{array}$ & $\begin{array}{c}\text { Particle } \\
\text { type }\end{array}$ & $\begin{array}{c}\text { Particle } \\
\text { mass } \\
(\mathrm{kg})\end{array}$ & $\begin{array}{c}\text { Water } \\
\text { mass } \\
(\mathrm{kg})\end{array}$ & $\begin{array}{c}\text { Annular } \\
\text { shell mass } \\
(\mathrm{kg})\end{array}$ \\
\hline 1 & 80 & 3.0 & 152 & 72 & $\mathrm{Glass}$ & 19.87 & 4.18 & 24.05 \\
2 & 80 & 3.0 & 203 & 123 & $\mathrm{Glass}$ & 51.76 & 12.95 & 64.71 \\
3 & 90 & 4.5 & 203 & 113 & $\mathrm{Glass}^{2}$ & 50.26 & 12.66 & 62.92 \\
4 & 90 & 4.5 & 203 & 113 & $\mathrm{ZrO}_{2}$ & 86.41 & 15.27 & 101.68 \\
5 & 90 & 4.5 & 229 & 139 & $\mathrm{ZrO}_{2}$ & 125.63 & 23.15 & 148.78 \\
\hline
\end{tabular}

Each charge was constructed with the aid of two thin-walled acrylic polymer, concentric spheres. Each spherical shell consisted of two hemispheres that were adhesively connected at the equator. The plastic hemispheres varied in thickness from $4.8 \mathrm{~mm}$ at the equator to $1.6 \mathrm{~mm}$ at the top of each hemisphere. Figure 3 shows the charge consisted of an internal sphere of radius, $R_{1}$, containing the explosive surrounded by an outer sphere of radius $\mathrm{R}_{2}$, defining the outer diameter of the sphere containing the granular material and test charge. The radius of both the inner and outer sphere was defined by the outside of the acrylic shell. The annular region between the two spheres was approximated by $\mathrm{R}_{2}-\mathrm{R}_{1}$ less the thickness of the outer acrylic shell (which varied between 1.6-4.8 $\mathrm{mm}$ ) and was filled with the water-saturated granular material.

The test charge assembly procedure began by filling the inner polymer sphere (with radius $\mathrm{R}_{1}$ ) with either $3 \mathrm{~kg}$ or $4.5 \mathrm{~kg}$ of $\mathrm{C} 4$ explosive. This sphere was then centered within the larger polymer sphere with radius $\mathrm{R}_{2}$. A carbon fiber reinforced polymer (CFRP) suspension rod was inserted through the center of both spheres to enable the charge to be later suspended above the test plate, Figure 2(a). The outer sphere was composed of two hemispheres, with a $3.8 \mathrm{~cm}$ circumferential flange that enabled them to be joined together with a high strength epoxy adhesive. A $10 \mathrm{~mm}$ diameter, cylindrical, thin-walled plastic pipe was inserted through the top of the outer and inner concentric spheres to provide access for subsequent placement of a detonator in contact with the $\mathrm{C} 4$ charge. The mass of the particles required for a random dense filling of the annular region was first calculated. The weight of the added particles was then measured as they were slowly poured into the annular space outside the center spherical explosive charge, until the annular shell was completely filled, and the calculated mass attained. To ensure dense random packing, the sides of the sphere were vibrated to ensure the particles were tightly packed. The calculated water mass needed to fill all the interparticle spaces was also calculated and this mass of water was poured 
into the granular particle filled cavity. Three test charges (Shots 1-3) used fused silica (glass) particles with a diameter of 150-200 $\mu \mathrm{m}$, Figure 4(a). These grade GL-0191 soda-lime glass particles from Mo-Sci Corporation (Rolla, Missouri) had a density of $2500 \mathrm{~kg} / \mathrm{m}^{3}$, and were identical to those used in previous tests with this experimental setup [11] and in several other lower impulse level tests $[10,17,23]$. Two of the charges (Shots 4 and 5) used zirconia particles obtained from Saint-Gobain (Huntsville, AL; product 9826 70/100), Figure 4(b). These particles had a similar effective diameter but were more angular in shape and had a much higher density of 5930 $\mathrm{kg} / \mathrm{m}^{3}$. Sufficient water was again added to fill the void space between the $\mathrm{ZrO}_{2}$ particles. The very high mass of these charges, Table 1, required the use of a coarse mesh net for their suspension over the test plates.

The charges were suspended above the center of the test plates as shown in Figure 2. Their standoff distance was defined from the charge center to the top of the test plate, $\mathrm{H}_{\mathrm{p}}$. The distance from the charge center to the end of a Kolsky bar, Figure 2, was defined by $\mathrm{H}_{\mathrm{k}} \approx \mathrm{H}_{\mathrm{p}}$. After set-up of the test arrangement, an instantaneous (zero millisecond delay) detonator manufactured by Dyno Nodel Inc. (Salt Lake City, Utah; model SP/SM (12-0)) was inserted into the explosive charge through the cylindrical, plastic pipe just before the detonation event. To ensure equivalent loading of both the test plate and end of the Kolsky bar, the charge orientation was adjusted as shown in Figure 2 and Figure 3, so that the detonator was situated $45^{\circ}$ to the East of the charges' North Pole. The significant mass of test Shot 5 made it difficult to suspend the charge at the desired rotation angle, and so this test used a detonator inclination angle $\theta=70^{\circ}$ (Figure 5).

The initial placement of the center of the test charge was $45 \mathrm{~cm}$ above the center of the test plate and $45 \mathrm{~cm}$ from the impact end of the Kolsky bar. However for each of the five test shots, enough time elapsed between test set-up and charge detonation that the charge location suffered some drift, resulting in small changes to the standoff distance between the charge center and end of the Kolsky bar and surface of the plate. The actual standoff distances, to the test plate and to the Kolsky bar were measured from the high-speed video images just prior to detonation and are summarized in Table 2.

Table 2. Standoff distances from the test charge center to the top of the test plate and impacted end of the Kolsky bar, measured from the high-speed videos prior to detonation.

Test shot Standoff to test plate Standoff to Kolsky bar $\mathrm{H}_{\mathrm{p}}(\mathrm{cm}) \quad \mathrm{H}_{\mathrm{k}}(\mathrm{cm})$ 


\begin{tabular}{lll}
\hline 1 & 41.7 & 41.6 \\
2 & 48.6 & 44.5 \\
3 & 44.6 & 44.6 \\
4 & 44.4 & 44.9 \\
5 & 45.6 & 45.3 \\
\hline
\end{tabular}

\subsection{Kolsky bar measurements}

In order to measure the impulse applied by the different test charges, a strain gage instrumented, $2.54 \mathrm{~cm}$ diameter, $3.81 \mathrm{~m}$ long (age hardened) C-350 grade maraging steel Kolsky bar was positioned $45 \mathrm{~cm}$ above the top of the test plate. To estimate the impulse applied to the center of the test plate, the end of the bar was placed at approximately the same distance from the center of the test charge as that to the top of the test plate center, Figure 3 and Table 2. Despite some experimental variability in these distances, the pressure applied to the Kolsky bar provided an experimental estimate of the loading experienced by the center of the test plates. It was also used to test the validity of a subsequent simulation of the test. After validation, this simulation was then used to determine the impulse distribution applied to the plate. The Kolsky bar was aligned such that its cylindrical axis intersected the center of the explosive charge using four adjustable height pedestal supports, Figure 2. The end of the bar experienced a considerable force during the tests, and was therefore clamped to each of the pedestals which in turn were bolted to a thick reinforced concrete foundation. The square cross section pedestals were rotated so that they presented $45^{\circ}$ symmetrically inclined faces to the ejecta to reduce the applied load. To reduce leakage of the Kolsky bar's elastic wave propagation modes [35], plastic bushings were placed on the Kolsky bar where it was secured to the pedestals, Figure 2(a).

Two, T-rosette type strain gauges (Vishay Precision group, CEA-06-125UT-350) were mounted $0.6 \mathrm{~m}$ from the impact end of the Kolsky bar to measure the axial stress (pressure) and transmitted impulse resulting from impact by the water saturated granular material. The strain gauges were bonded to the bar diametrically opposite each other with Vishay AE-10 epoxy adhesive. A protective coating (Vishay Gage Kote \#5) was applied to the strain gauges and the connecting wires for protection from the test events. The wires led to a digital signal recording system located in a metal box to the side of the test arrangement and covered with sand bags for protection from the blast events. For the full Wheatstone bridge circuit, the relationship between the input, $V_{i}$ and output $V_{o}$ voltages is described by; 


$$
\frac{V_{o}}{V_{i}}=\frac{G F * \varepsilon(1+v)}{2+G F * \varepsilon(1-v)}
$$

Here, GF $=2.15$ is the gage factor of the selected strain gage, $\varepsilon$ the strain on the Kolsky bar, and $v$ $=0.28$ Poisson's ratio of the bar. Test Shots 1 and 2 used an input excitation voltage $V_{i}=10 \mathrm{~V}$ while test Shots 3-5 used $V_{i}=5 V$ to keep the signal amplitude from overloading the analogue to digital converter. A low-pass filter applied an upper cutoff frequency of $1 \mathrm{MHz}$ to the recorded signal. The axial strain deduced from the data using equation (1) was used with Hooke's law to determine the axial stress (applied pressure) on the Kolsky bar, and by its time integration, the impulse transmitted to the bar.

For each test shot, signal recording was initiated by a break wire that was attached to the external surface of the test charge. For consistency, $\mathrm{t}=0 \mathrm{~s}$ was defined as the time of detonation of the event. Since the trigger wire was attached to the outer shell of the test charge, this meant there was a delay from the time of detonation until the trigger signal was initiated. To adjust for this delay, the data for each test charge was shifted by the time for a detonation wave to propagate through the explosive and for a shock wave to penetrate the shell of granular material, break its surface and trigger the recoding system. Appendix A presents discrete particle simulations of the charge detonation and shock compression of the granular materials surrounding the charge. These simulations enabled the detonation and granular shock transit times to be estimated, Table 3.

Table 3. Time for detonation and shock propagation through the explosive and granular shells.

\begin{tabular}{cccccc}
\hline $\begin{array}{c}\text { Test } \\
\text { shot }\end{array}$ & $\begin{array}{c}\text { Explosive } \\
\text { radius, } \\
\mathrm{R}_{1}(\mathrm{~mm})\end{array}$ & $\begin{array}{c}\text { Outer } \\
\text { radius, } \\
\mathrm{R}_{2}(\mathrm{~mm})\end{array}$ & $\begin{array}{c}\text { Detonation wave } \\
\text { transit time } \\
(\mu \mathrm{s})\end{array}$ & $\begin{array}{c}\text { Granular material } \\
\text { shock transit time } \\
(\mu \mathrm{s})\end{array}$ & $\begin{array}{c}\text { Total delay } \\
\text { time } \\
(\mu \mathrm{s})\end{array}$ \\
\hline 1 & 80 & 152 & 20 & 20 & 40 \\
2 & 80 & 203 & 20 & 34 & 54 \\
3 & 90 & 203 & 22 & 31 & 53 \\
4 & 90 & 203 & 22 & 36 & 58 \\
5 & 90 & 229 & 22 & 45 & 67 \\
\hline
\end{tabular}

The Kolsky bar data has been time-shifted to maintain a consistent definition of time $(\mathrm{t}=0 \mathrm{~s}$ as the moment of detonation) by adding the time delay between initiation of detonation and breakage of the trigger wire, whereupon signal recording was started, Table 3. The strain gauge sensors from which the pressure was deduced were positioned $0.6 \mathrm{~m}$ from the impacted end of the Kolsky bar. The signal at the strain gauge location was therefore delayed by the time for the longitudinal elastic wave to propagate along the $0.6 \mathrm{~m}$ distance in the bar. Since the longitudinal 
elastic wave speed in C-350 maraging steel bar is $4800 \mathrm{~m} / \mathrm{s}$, it required $125 \mu \mathrm{s}$ for a signal, caused by impact with the end of the bar, to reach the sensor location. The first reflection from the distal end of the Kolsky bar (length $3.81 \mathrm{~m}$ ) arrived $1.38 \mathrm{~ms}$ after the initial signal. To avoid complexities associated with this reflected signal, only data prior to the arrival of the distal reflection was used.

\section{Simulation Methodology}

The five test shots were simulated using the IMPETUS Afea Solver [34]. This solver uses a discrete particle blast code that tracks collisions between air, soil, and high explosive (HE) particles using a particle contact model. A full description of the solver can be found in Borvik et al. [34] and Olovsson et al. [32]. Its validation for the water saturated soda lime glass particle "sand" used here has been presented by Kyner et al. [11] and by Borvik et al. [34] using a similar experimental test [17], but at much lower impulse level. Several prior studies have shown this solver to be a reasonably accurate tool for the analysis of high intensity granular loading problems $[10-12,23,34]$. Briefly, the solver is based on a Lagrangian formulation in which the discrete particles are fully coupled and allowed to interact with a finite element (FE) model of a test structure. The particles momentum transferring collisions are governed by a contact interaction model. To reduce computational time, all the particles were assumed spherical in shape with three translational degrees of freedom. Consequently, particle rotation and the transfer of angular momentum during collisions was not treated. This is equivalent to the assignment of an infinite moment of angular inertia to the particles. Furthermore, the effects of particle fracture were not modeled by the solver. It is presumed that a previous calibration of the contact model parameters has compensated for much or the error introduced by use of these simplifying assumptions.

\subsection{The particle contact model}

Air and HE particles were modeled as rigid, spherical particles with elastic particle interactions consistent with Maxwell's kinetic theory of gases [32]. The air is treated as an ideal gas with a density $\rho=1.3 \mathrm{~kg} / \mathrm{m}^{3}$. The air particles were given an initial translational energy $\mathrm{E}_{0}=$ $253 \mathrm{~kJ} / \mathrm{m}^{3}$ and a ratio of heat capacities $\gamma=1.4$. The initial particle velocities and directions attributed to each particle were randomly selected from the Maxwell-Boltzmann distribution. The HE particles were modeled using the solver's predetermined parameters for $\mathrm{C} 4$ explosive. This 
ascribes an initial density $\rho=1601 \mathrm{~kg} / \mathrm{m}^{3}$, an initial internal energy $\mathrm{E}_{0}=8.7 \mathrm{GJ} / \mathrm{m}^{3}$, a heat capacity ratio $\gamma=1.4$, a particle initial solid-fill fraction $b=0.35$, and a detonation velocity $\mathrm{D}=8190 \mathrm{~m} / \mathrm{s}$.

Interactions between the soil particles were treated using a soft particle, penalty contact model [34]. For test Shots 1-3 with glass particles, the solver's predefined wet sand parameters were used in the model. This data set had been obtained by calibration [34] of an earlier experimental study [17] using the same 150-200 $\mu \mathrm{m}$ diameter, soda lime glass particles used here. The wet sand model used by the solver does not model the soil particles and water separately. Rather the particle parameters are adjusted to account for the effects of the water as described by Borvik et al. [34]. These particle parameters for the wet synthetic (glass particle) sand gave an initial density $\rho=$ $2020 \mathrm{~kg} / \mathrm{m}^{3}$, a soil-soil contact stiffness $k_{0}=4.0 \mathrm{GN} / \mathrm{m}$, a soil-soil contact coefficient of friction $\mu$ $=0.0$, and a soil-soil damping coefficient $\xi=0.005$. The zirconia particles had a dry bulk density of $\rho=2550 \mathrm{~kg} / \mathrm{m}^{3}$ with a $43 \%$ fill fraction. Water was added to fill in the voids, resulting in a measured water saturated density $\rho=3120 \mathrm{~kg} / \mathrm{m}^{3}$. To model the zirconia particles within the solver, a series of simulations were conducted in which the stiffness, friction, and damping coefficients were systematically adjusted from the wet glass particle parameters until the impulse applied to the Kolsky bar and the sand front propagation velocity correlated with experimental observations. This resulted in a soil-soil contact stiffness $k_{0}=4.5 \mathrm{GN} / \mathrm{m}$, a soil-soil contact coefficient of friction $\mu=0.05$, and soil-soil damping coefficient $\xi=0.005$. A particle convergence study indicated simulation convergence with two million particles, and so this number of particles was used for all the tests. The division of the two million particles between air, soil, and HE particles was determined by the solver, and since the volume of soil and high explosive was different for each test shot, the particles were distributed differently for each test, Table 4.

Table 4. Distribution of air, HE, and soil particles in the simulations for each test shot.

\begin{tabular}{cccc}
\hline Test shot & Air particles & HE particles & Soil particles \\
\hline 1 & 854,468 & 701,310 & 444,222 \\
2 & 617,032 & 514,705 & 868,263 \\
3 & 556,265 & 688,420 & 755,495 \\
4 & 556,838 & 686,445 & 756,717 \\
5 & 468,425 & 585,587 & 945,987 \\
\hline
\end{tabular}

\subsection{FE geometry model}

The charge position dependent geometry of each test was used to construct finite element models as shown in Figure 5. The FE models for the test plate, support platform, and Kolsky bar 
were the same for all the test simulations. However, the suspended explosive test charge was shifted based on the standoff distances, $\mathrm{H}_{\mathrm{p}}$ and $\mathrm{H}_{\mathrm{k}}$, measured from the high-speed cameras, Table 2. The experimentally determined dimensions of the Kolsky bar, test platform support frame, and the $2.54 \mathrm{~cm}$ thick stainless steel test plate were used to construct the model. The Kolsky bar was modeled using a bar diameter of $2.54 \mathrm{~cm}$ and total length of $3.81 \mathrm{~m}$. It was constructed in four cylindrical sections, with a $4 \mathrm{~mm}$ length cylinder at $0.6 \mathrm{~m}$ from the impacted end included to represent the strain gauge location. A small 2.54 length cylindrical section at the front of the bar was used to calculate the initial impact force. The pressure applied to the bar was calculated by dividing the force-time response of the elements in the $4 \mathrm{~mm}$ length cylinder by the cross-sectional area of the bar. Temporal integration of this pressure-time signal was used to obtain the specific impulse transferred to the Kolsky bar. The Kolsky bar FE model consisted of 39,432 linear hexahedra elements and 44,120 nodes.

The test rigs support frame was modeled as two solid block picture frames with external dimensions of $1.22 \mathrm{~m} \times 1.22 \mathrm{~m}$ with an $81.3 \mathrm{~cm} \times 81.3 \mathrm{~cm}$ center opening. The thickness of the upper block was $5.08 \mathrm{~cm}$ while that of the bottom was $15.2 \mathrm{~cm}$. The four bolts used to secure the plates to the support rig at its four corners were included in the model. The bottom plane of this support frame was constrained in all directions. The stainless steel test plate was given dimensions of $1.32 \mathrm{~m} \times 1.32 \mathrm{~m}$ and a thickness of $2.54 \mathrm{~cm}$. In order to clamp the plate to the support frame, an outer, $5.1 \mathrm{~cm}$ wide and $2.54 \mathrm{~cm}$ thick picture frame was connected to the solid plate using the solver's merge option. This represented the four rectangular bars that had been joined to the outer edge of the plate. The solid test plate and four attached rectangular bars forming the outer edge of the picture frame, were modeled with a refined mesh (to enhance observation of plate deformation) using 1,492 cubic hexahedra elements with 56,100 nodes.

The suspended charge was modeled as an inner sphere of outer radius $\mathrm{R}_{1}$ that contained the explosive surrounded by an annulus of granular material with outer radius, $\mathrm{R}_{2}$. The acrylic plastic shell that retained the explosive particles and the outer plastic shell that contained the granular particles were included in the model. To simplify the model, each polymer shell was given a fixed thickness of $3 \mathrm{~mm}$. Since the flange that connected the outer hemispheres did not influence the impulsive load applied to the test plate or Kolsky bar, it was not included in the model. The detonation location of the test charge was set at the outer edge of the explosive sphere, at $\theta=45^{\circ}$ 
for Shots 1-4 and at $70^{\circ}$ for Shot 5, Figure 5. The full FE meshed model (the support structure, test plate, four bolts, Kolsky bar, and acrylic shells) consisted of 43,404 elements (432 linear pentahedra, 1,492 cubic hexahedra, and 41,480 linear hexahedra elements) with 214,202 nodes.

\subsection{Material parameters}

A Johnson-Cook model was used to represent the constitutive response of the solid materials in the finite element model. This included the 304 stainless steel test plates, the A-36 support frame, the C-350 grade (age hardened) maraging steel Kolsky bar, and the carbon steel bolts. The solver calculates the von Mises flow stress for the Johnson-Cook constitutive model by

$$
\sigma_{y}=\left(A+B\left(\left(\varepsilon_{e f f}\right)^{n}\right)\right) \cdot\left(1+C \ln \frac{\dot{\varepsilon}_{e f f}}{\dot{\varepsilon}_{0}}\right) \cdot\left(1-\left(\frac{T-T_{0}}{T_{m}-T_{0}}\right)^{m}\right)
$$

The model for each material is defined by constants for the initial yield strength A, the strain hardening parameters $\mathrm{B}$ and $\mathrm{n}$, the strain rate hardening parameters $\mathrm{C}$ and $\dot{\varepsilon}_{0}$, the thermal softening parameter $\mathrm{m}$, and the effective plastic strain, $\varepsilon_{e f f}$, the melting temperature $T_{m}$ and the ambient temperature $T_{0}$. The Johnson-Cook parameters for each material are listed in Table 5. The test plate was modeled with parameters for annealed 304 stainless steel [36, 37]. The parameters for A-36 steel were taken from ASTM-A36 [38]. The parameters for the 350 grade maraging steel were those of a similar, VascoMax 300 alloy [39], but with an adjusted yield strength of 2.195 $\mathrm{GPa}$ to better represent the C-350 grade steel used here [40]. The Grade 8 steel bolt parameters were assumed to be the same as medium carbon steel AISI 1040 [41]. Since no fracture was observed in the experimental tests, a failure model was not included in the simulations. The plastic spherical shells containing the inner charge and the outer annulus of wet sand were modeled using an elastic constitutive model with parameters for acrylic plastic, $\rho=1180 \mathrm{~kg} / \mathrm{m}^{3}$, Young's modulus $\mathrm{E}=2.80 \mathrm{GPa}$, and Poisson's ratio $v=0.37$. Failure was set at a strain of $10 \%$ at which point the failed elements were eroded.

Table 5. Material constants for 304SS, A-36 steel, C-350 maraging steel, and medium carbon steel AISI 1040.

\begin{tabular}{cccccccccccc}
\hline Material & \multicolumn{2}{c}{$\begin{array}{c}\text { Density and } \\
\text { elastic constant }\end{array}$} & \multicolumn{3}{c}{$\begin{array}{c}\text { Yield stress and } \\
\text { strain hardening }\end{array}$} & \multicolumn{2}{c}{$\begin{array}{c}\text { Strain rate } \\
\text { hardening }\end{array}$} & $\begin{array}{c}\text { Temperature softening } \\
\text { and adiabatic heating }\end{array}$ \\
\hline & $\begin{array}{c}\rho \\
\left(\mathrm{kg} \cdot \mathrm{m}^{-3}\right)\end{array}$ & $\begin{array}{c}\mathrm{E} \\
(\mathrm{GPa})\end{array}$ & $v$ & $\begin{array}{c}\mathrm{A} \\
(\mathrm{MPa})\end{array}$ & $\begin{array}{c}\mathrm{B} \\
(\mathrm{MPa})\end{array}$ & $\mathrm{n}$ & $\mathrm{C}$ & $\begin{array}{c}\varepsilon_{0} \\
\left(\mathrm{~s}^{-1}\right)\end{array}$ & $\begin{array}{c}\mathrm{T}_{0} \\
(\mathrm{~K})\end{array}$ & $\begin{array}{c}\mathrm{T}_{\mathrm{m}} \\
(\mathrm{K})\end{array}$ & $\mathrm{m}$ \\
\hline $304 \mathrm{SS}$ & 7900 & 200 & 0.3 & 310 & 1000 & 0.65 & 0.07 & 1.0 & 293 & 1673 & 1.0
\end{tabular}




\begin{tabular}{lccccccccccc} 
A-36 & 7850 & 199 & 0.3 & 244 & 484 & 0.235 & 0.0165 & 0.0002 & 300 & 1790 & 1.03 \\
C-350 & 7900 & 180.7 & 0.283 & 2195 & 9400 & 1.175 & 0.0046 & 1.0 & 300 & 1685 & 0.78 \\
AISI 1040 & 7845 & 200 & 0.28 & 533 & 601 & 0.234 & 0.0134 & 1.0 & 293 & 1733 & 1.0 \\
\hline
\end{tabular}

\section{Experimental Results}

\subsection{Sand front propagation}

\subsubsection{High speed video observations}

The radial expansions of the particle fronts for the three glass particle tests (Shots 1-3) can be seen in the high-speed video images of Figure 6. These expansions were accompanied by an air shock front (not visible in these figures but shown later) that propagated slightly ahead of the particle fronts. The upper row of images shows the test configuration at the instant of detonator activation $(t=0 \mathrm{~s})$. The white painted edge of the test plate specimen and the end of the Kolsky bar provide a length scale for interpretation of the images. The three vertical image columns show the radial expansion of the glass particle fronts at $\sim 250 \mu$ s and $\sim 650 \mu$ s after detonation for each test charge. A significant local retardation of the sand front by the wide polymer flanges can be seen, but the charge orientation ensured that this had no effect on the impulse loading of the Kolsky bar or test plate. In the image column for Shot 1, Figure 6(a) to (c), the rapid radial expansion of the glass particle front resulted in almost simultaneous impact of the granular material with the end of the Kolsky bar and the center of the test plate shortly after $250 \mu \mathrm{s}$, Figure 6(b). The lowermost image, Figure 6(c), shows the configuration at $650 \mu \mathrm{s}$ after detonation when the spherical sand front had made complete contact with the top surface of the test plate. The magnified inset in this image shows the presence of sand fingers, corresponding to spikes of granular material at the leading edge of the sand front with a substantially higher tip velocity compared to the main sand front. Luminescence (white dots) is evident at the tips of a few of these sand fingers.

The effect of increasing the thickness of the sand shell (without changing the explosive mass) can be seen by comparing the images for test Shots 1 and 2. Comparison of Figure 6(b) and (e) with Figure 6(c) and (f) shows that the radial expansion rate was significantly higher for Shot 1 with a lower (water saturated) glass particle mass. In contrast, comparison of test Shots 2 and 3 enables the effect of increasing the explosive to be observed. Figure 6(h) shows luminescence associated with the impact of glass particles with the test plate and (simultaneously) with the end of the Kolsky bar at $\sim 288 \mu$ s after detonation. Contact of the glass particles began at $\sim 270-280 \mu \mathrm{s}$ after detonation. Comparison of the Shot 2 and 3 images in Figure 6(f) and (i) at about 666 and 
$636 \mu$ s after detonation, indicates the sand travelled significantly further for Shot 3, consistent with an increase of the explosive mass resulting in a higher radial glass particle front expansion rate. The sand finger phenomenon can also be clearly seen in the magnified inset of Figure 6(i) for Shot 3 as well as occasional fingertip luminescence. The fingering instability present in Shot 2 was not as prominent as that seen in the two other higher glass particle expansion rate test shots.

Analogous observations of the radial expansion of the (water saturated) zirconia particle fronts can be seen in Figure 7. The times after detonation for these images were similar to those in Figure 6. Note that Shots 3 and 4 used the same mass of explosive and granular material shell thickness $\left(\mathrm{R}_{2}=203 \mathrm{~mm}\right)$, but Shot 4 used a granular shell filled with higher density zirconia particles. Comparison of the third column of Figure 6 with the first of Figure 7 shows that increasing the granular shell density (and mass) significantly reduced the shell's radial expansion rate. This delayed the arrival of the granular material at the end of the Kolsky bar, and with the top of the test plate. This lower velocity expansion was also accompanied by a much less prominent fingering instability, Figure 7(c). The consequence of increasing the zirconia particle shell thickness (and mass) can be seen by comparing the first and second columns of Figure 7. The first impact of granular material with the test plate for Shot 5 occurred slightly before $t=641 \mu$ s after detonation, Figure 7(f). This was more than double the time required for the glass particles in test Shot 3 to arrive at the plate, Figure 6(h). In that case, first impact with the test plate occurred $280 \mu$ s after detonation. The fingering instability was almost absent in Shot 5, Figure 7 (f) which exhibited the slowest particle expansion velocity of the five tests.

The high-speed video images were used to track the granular material main front position (from which the fingering instability emanated) as it radially expanded after detonation. This sand front position data is plotted in Figure 8(a) for the glass particle test shots and in Figure 9(a) for the zirconia tests. Numerical differentiation of the position data was used to estimate the radial expansion velocity of the fronts. This data is plotted in Figure 8(b) for the glass particle tests and in Figure 9(b) for the zirconia particle tests. The velocity errors were calculated using the methodology described in [11]. In all cases, the radial expansion rates rapidly increased to a maximum value typically attained at approximately 100-200 $\mu$ s after detonation. This was followed by an extended period of gradual particle deceleration. The highest radial expansion velocity for the main sand front was approximately $1210 \mathrm{~m} / \mathrm{s}$ for Shot 1, Figure $8(\mathrm{~b})$, while the 
lowest peak velocity of approximately $490 \mathrm{~m} / \mathrm{s}$ was observed for Shot 5, Figure 9(b). The peak radial expansion rates and times for the main particle fronts to reach the end of the Kolsky bar are summarized in Table 6 for the five tests.

Table 6. The impact times of the main particle front with the Kolsky bar deduced from experimental main particle front position and the peak velocity for each test charge. The calculated air shock pressures and speeds are also listed.

\begin{tabular}{cccccc}
\hline Test Shot & $\begin{array}{c}\text { Impact Time } \\
(\text { Kolsky bar }) \\
(\mu \mathrm{s})\end{array}$ & $\begin{array}{c}\text { Peak velocity } \\
(\text { main front }) \\
(\mathrm{m} / \mathrm{s})\end{array}$ & $\begin{array}{c}\text { Air shock } \\
\text { pressure, } p_{f} \\
(\mathrm{MPa})\end{array}$ & $\begin{array}{c}\text { Air shock } \\
\text { speed, } c_{f} \\
(\mathrm{~m} / \mathrm{s})\end{array}$ & $\begin{array}{c}\text { Simulation } \\
\text { max air speed } \\
(\mathrm{m} / \mathrm{s})\end{array}$ \\
\hline 1 & $275 \pm 20$ & 1210 & 2.3 & 1518 & 1250 \\
2 & $405 \pm 10$ & 780 & 1.1 & 1048 & 770 \\
3 & $300 \pm 19$ & 980 & 1.6 & 1291 & 940 \\
4 & $515 \pm 10$ & 600 & 0.7 & 857 & 745 \\
5 & $580 \pm 8$ & 490 & 0.55 & 756 & 605 \\
\hline
\end{tabular}

The data in Table 6 for Shots 1 and 2 indicate that when the mass of granular material in the annularly filled region was increased (Table 1) while keeping that of the explosive fixed, the front maximum particle front velocity decreased from $1210 \mathrm{~m} / \mathrm{s}$ to $780 \mathrm{~m} / \mathrm{s}$. Increasing the explosive mass from $3 \mathrm{~kg}$ (Shot 2) to $4.5 \mathrm{~kg}$ (Shot 3), while keeping the granular material outer radius fixed, resulted in an approximately $200 \mathrm{~m} / \mathrm{s}$ increase in sand front velocity. Switching from glass particles to (denser) zirconia particles, while keeping the geometry and explosive mass fixed, significantly reduced the sand front velocity from $980 \mathrm{~m} / \mathrm{s}$ (Shot 3) to $600 \mathrm{~m} / \mathrm{s}$ (Shot 4), and resulted in substantial delay $(\sim 250 \mu \mathrm{s})$ in particle front impact with the Kolsky bar and test plate. Finally, increasing the mass of the zirconia while keeping the explosive mass constant decreased the maximum front speed from $600 \mathrm{~m} / \mathrm{s}$ (Shot 4) to $490 \mathrm{~m} / \mathrm{s}$ (Shot 5) and consequently also increased the time to impact on the Kolsky bar by $90 \mu \mathrm{s}$.

\subsubsection{Particle shell expansion simulations}

The high-speed video observations only enable visualization of particle motions near the exterior surface of the charges during a test event. These observations provided no insight into processes occurring behind the particle fronts, nor quantitative information about the air shocks that developed ahead of the supersonically expanding granular media. Discrete particle 
simulations of the test shots do not suffer from sand particle or high explosive product obscuration of the event interior. Consequently, they can be used to investigate the transfer of momentum from detonation products to the granular material, the interactions of these particles with background air and solid targets, and for calculation of the impulse transferred during particle impact with the targets.

Activation of detonation on the Northeast surface of the explosive resulted in the propagation of a detonation wave through the explosive core and transmission of a compressive shock through the granular media. Simulations of shock front propagation through the explosive and the water saturated particles are shown for the five test shots in Figures A1 (Shots 1-3) and A2 (Shots 4 and 5) in Appendix A. The time between activation of detonation and the initiation of particle escape from the charges (by particle spallation at the sand/air interface) depended on charge diameter and varied from 40-67 $\mu$ s, Table 3. These times were therefore used to correct the time measured after the trigger event (the breaking of a wire on the exterior of the test charges) so that both the highspeed video and Kolsky bar data used time $t=0 \mathrm{~s}$ to signify the initiation of detonation.

The diametral plane from the simulations of the glass particle tests (Shots 1-3) are shown in Figure 10. The simulation times, $\mathrm{t}=0 \mathrm{~s}, 250 \mu \mathrm{s}$, and $650 \mu \mathrm{s}$, correspond to those of the high-speed video images, Figure 6. Figure 10(a), (d), and (g) show the center cross section of the test plate, support structure, Kolsky bar, and test charge at $t=0 \mathrm{~s}$ (initiation of detonation). Comparison of Shots 1 and 2 in Figure 10 reveals the effect of changing the granular shell thickness (and mass) while comparison of Shots 2 and 3 indicates the effects of changing the radius of the explosive core (or explosive mass). These results show that for Shot 1 particle impact with the Kolsky bar and test plate had begun at about $\mathrm{t}=250 \mu \mathrm{s}$ after detonation. They also show that increasing the thickness of the granular shell (by comparing Shot 1 and Shot 2) slowed the rate of radial particle expansion in the test plate and Kolsky bar directions. This expansion velocity was then increased by increasing the radius/mass of the explosive core (Shot 3 ).

The simulations at $\mathrm{t}=650 \mu \mathrm{s}$ after detonation, Figure 10(c), (f), and (i) show that for Shot 1 the particles impacting the test plate and the loading of the (darker red) detonation product had progressed further than for the other two shots (Shots 2 and 3), consistent with its higher radial particle velocity. A small rebound of the granular particles occurred where they made perpendicular impact near the test plate center, but this was suppressed by impacts with later arriving particles, resulting in particle accumulation on the test plate. Oblique particle impacts 
towards the sides of the test plate resulted in the reflection with a horizontal direction component and the formation of a particle layer close to the sample surface that flowed laterally off the edge of the test structure (see lower left of Figure 10(c)). Initial deflection of the test plate can also be seen to have occurred by this time.

Figure 11 shows analogous results for Shots 4 and 5 that used higher density zirconia particles. Note that the detonator location for Shot 5 was $70^{\circ}$ from horizontal rather than $45^{\circ}$ used in the other tests. Comparison of Figure 10(h) and (i) with Figure 11(b) and (c) show that increasing the mass of the granular shell by use of higher density particles significantly reduced the radial expansion rate as observed experimentally. Impact of granular particles with the test plate for Shot 5, Figure 11(f), occurred slightly before $650 \mu \mathrm{s}$; almost $400 \mu \mathrm{s}$ later than that observed for Shot 1 , Figure 7(b).

The sand front radially expanded outward in a slightly asymmetric manner with the highest particle velocity diametrically opposite the point of detonation (the direction of longest cord length in the explosive), Figures A1 and A2. As the sand shell expanded, a velocity and thus particle density gradient developed between the front and back of the expanding granular medium. The leading edge of this expanding particle shell consisted of a low volume fraction of high velocity particles that were spalled from the shell surface during first reflection of the shock at the granular material-air interface. These fast sand particles had a speed consistent with that of the sand fingers seen in the high-speed video images. Comparison of Figure 10 and Figure 11 indicates that the zirconia test shots had a lower concentration of fast particles at the leading edge of the zirconia particle front consistent with the experimentally observed decrease in sand fingers. The trailing edge of the granular particle shell was composed of a high density of low velocity solid particles that were "pushed" by the expanding detonation product particles. An air shock (not shown in Figure 10 and Figure 11) formed ahead of the expanding particle front with a maximum speed between $605-1250 \mathrm{~m} / \mathrm{s}$ that increased with particle shell peak velocity (Table 6).

The region of highest velocity particles was consistent with that occupied by the sand fingers observed experimentally at the leading edge of the sand front. The discrete particle based simulation approach was unable to resolve the evolving surface topology of the instability responsible for sand fingering. However, a recent study by Kyner et al. [11] has applied a result by Kandan et al. [42] to show that the instability originates from the growth of surface perturbations with shapes that suffer the lowest air drag as they penetrate the high air pressure 
immediately in front of the expanding particles. As the sand front is supersonically pushed outward through the background air with velocity $V_{S}$, an air shock develops ahead of the sand with a shock pressure $p_{f}$ and speed $c_{f}$ [42]. The air shock that developed was observed in the high-speed video for Shot 2 and can be seen in Figure 12(a) and (b) as an opaque region propagating outward ahead of the sand front. Figure 12(a) shows the air shock wave at $333 \mu$ s just before the shock front impacted the Kolsky bar while Figure 12(b) shows it at later time (555 $\mu$ s after detonation). The insets give a magnified view of the air shock and use a dashed line to show the shock front position. Simulation of Shot 2 at approximately the same times are also shown in Figure 12(c) and (d). They show the densified shocked region of (blue) air particles that developed ahead of the sand front increased in thickness over time since the air shock velocity exceeded that of the particle front.

The air shock pressures and speeds for each test shot were calculated by the method presented in Kandan et al. [42], and are summarized along with the sand front velocities in Table 6. The calculated air shock velocities slightly exceeded those determined from the simulations. It is interesting to note that as the air pressure ahead of the expanding particles decreased (from Shot 1 to Shot 5), the presence of the finger-like instability declined (see the insets of Figure 6(c) and Figure 7(f)).

The simulated sand front positions are plotted in Figure 8(a) and Figure 9(a) and found to be in good agreement with the experimentally observed sand front positions. The prolonged period of granular particle deceleration only occurred when background air particles were present in the simulations, consistent with momentum transfer from particles of the granular material to the background air. The peak in granular particle velocity then resulted from the initial transfer of momentum to the solid particles during shock reflection at the particle-air interface of the test charges, followed by solid-air particle collisions which reduced the momentum (and speed) of the solid particles during their propagation towards the target.

\subsection{Kolsky bar responses}

The applied pressure (axial stress) determined from the Kolsky bar strain gage measurements are shown in Figure 13 for the glass particle tests (Shots 1-3) and in Figure 14 for the zirconia particle tests (Shots 4 and 5). Recall that the time for an extensional wave to travel from the impacted end of the Kolsky bar to the strain gauges (where signals were detected) was $125 \mu \mathrm{s}$. 
Events at the end of the bar observed in the high-speed video images and the simulations therefore correspond to features that appear in the Kolsky bar signals $125 \mu$ s later in time.

Examination of the experimentally measured pressure-time responses in Figure 13 and Figure 14 reveals the presence of an initial, small pressure pulse. This signal was not clearly observable in the noisy pressure data of Shot 1, Figure 13(a), but the integrated response shown in Figure 13(d) began to rise at about $\sim 350 \mu$ s after detonation consistent with a weak pressure signal in the noisy data. For Shot 2, Figure 13(b), this first pulse was observed at $\sim 515 \mu$ s and at $\sim 395 \mu$ s after detonation in Shot 3 Figure 13(c). These three signals correspond to the application of a load at the end of the Kolsky bar at $\sim 225,390$, and $270 \mu$ s after detonation of test Shots 1, 2, and 3 respectively. Recall that Figure 6(b) and (h) showed high-speed video images from Shots 1 and 3 at 250 and $288 \mu \mathrm{s}$ after detonation respectively. The small increases in pressure evident in the pressure versus time waveforms in Figure 13 correspond to the arrival of the air shock and fastest sand fingers slightly ahead of the main sand front whose arrival times are summarized in Table 6.

Figure 14 shows the measured Kolsky bar pressure waveforms for the Shots 4 and 5 which used zirconia particles. The first small rise in pressure occurred substantially later for the zirconia test shots, Figure 14(a)-(b). For Shot 4, this first rise in pressure occurred at $\sim 620 \mu$ s corresponding to loading of the end of the Kolsky at about $495 \mu$ s after detonation. The first pressure rise for Shot 5 was observed at $\sim 695 \mu \mathrm{s}$ after detonation corresponding to the application of pressure at the end of the Kolsky at about $570 \mu \mathrm{s}$ after detonation. Careful analysis of the high-speed video results indicated first granular impact with the end of the Kolsky bar by the main particle front (since there was very little particle fingering) occurred at $515 \pm 10 \mu \mathrm{s}$ for Shot 4 and at about $580 \pm 8 \mu \mathrm{s}$ for Shot 5, Table 6. When the signal travel time in the Kolsky bar $(125 \mu \mathrm{s})$ is added to these first contact times, Figure 14(c) and (d) show they correspond to the beginning of the rise in impulse.

The initial rise in pressure was followed by a $100-200 \mu$ s period of weakly oscillating waveform until a sharp, much larger, pressure pulse was observed in all the tests, Figure 13and Figure 14. The large pressure pulses were followed by stronger oscillations resulting from the arrival of slower propagating Pochhammer - Chree bar modes [28, 35, 43]. The peak (compressive) pressure transmitted by the glass particle Shot 1 (Figure 13(a)) was $950 \mathrm{MPa}$. This was slightly higher than the $825 \mathrm{MPa}$ applied by Shot 2 (Figure 13(b)) which used the same mass of explosive 
but whose water saturated particle shell mass had been increased from 24 to $65 \mathrm{~kg}$, Table 1 . However, prior to detonation of Shot 1, the center of the charge suffered a $3.37 \mathrm{~cm}$ displacement towards the Kolsky bar, reducing the standoff distance in this direction, Table 2, and therefore increasing the speed and density of the granular media that contacted the end of the bar. Simulations where the standoff distance from the center of the test charge to the front of the Kolsky bar was $\mathrm{H}_{\mathrm{k}}=45 \mathrm{~cm}$ revealed that the pressure was increased slightly from Shot 4 to Shot 5 (by about $3 \%)$.

Examination of Figure 13(b) and (c) indicates that as the diameter (and mass) of the explosive core was increased while reducing the mass of the granular shell, the peak pressure for Shot 3 increased from $825 \mathrm{MPa}$ to $1250 \mathrm{MPa}$. The effect of changing the density of the granular particles while maintaining all other charge variables fixed can be seen by comparing the peak pressure of $\sim 1450 \mathrm{MPa}$ for Shot 4, Figure 14(a), with that of Shot 3 ( 1250 MPa). Examination of Figure 14(b) shows that the peak pressure decreased slightly to $\sim 1400 \mathrm{MPa}$ for Shot 5. When the thickness (and therefore mass) of the zirconia particle shell was increased while keeping the explosive mass fixed, the peak pressure was slightly reduced. However, the detonator inclination for Shot 5 was $\theta=70^{\circ}$ (compared to $\theta=45^{\circ}$ for Shots $1-4$, Figure 5) which slightly reduced the impulse in the Kolsky bar direction. A simulation with the corrected inclination angle for the detonator at $\theta=45^{\circ}$ revealed that the impulse applied to the Kolsky bar was approximately 2 $\mathrm{kPa} \cdot \mathrm{s}$ greater than when the detonator was inclined at $\theta=70^{\circ}$. Since the granular media had engulfed the end the Kolsky bar, the physical processes responsible for these jumps in pressure could not be deduced from the high-speed video observations.

Integration of the pressure signal gave the measured impulse-time response at the Kolsky bar sensor location. This is shown in Figure 13(d-f) for the glass particle shots and in Figure 14(c) and (d) for the zirconia shots. The five impulse-time responses all exhibited four characteristic regimes. They all showed an initial small jump in impulse at the time when the first small pressure pulse was observed (Region I). Examination of Figure 6 for the glass particle tests shows that this occurred as the fastest particles (sand fingers) emitted by the test charges began to make contact with the end of the bar. No fingers were present in the more slowly expanding zirconia particle tests (Figure 7), and in their case, the first impulse was associated with the main particle front contact. This region was followed by a period of slowly rising 
impulse (Region II) corresponding to the weakly oscillatory period between the initial pressure pulse and the strong pressure peak pressure. The simulations, Figures 10 and 11 indicate the start of Region II coincided with the arrival at the Kolsky bar location, of the main sand front (particles immediately behind the sand fingers), Table 6 . This region was characterized by a gradual rise in the particle density. Region III corresponded to the sudden jump in impulse associated with the peak in pressure. Examination of the simulations, Figure 11(f), shows that this coincided with the arrival of dense, but lower velocity sand that had been pushed to the end of the Kolsky bar by the expanding detonation product gas particles. This was then followed by an oscillatory response (a result of various bar mode elastic arrivals) whose average impulse fluctuated around a plateau value (Region IV) which is summarized for each test shot in Table 7. This plateau value was reached as the last of the solid (sand) particles and the leading edge detonation products made impact with the bar. The arrival of the remaining detonation products contributed very little additional impulse.

Table 7. The experimentally measured and simulated impulse applied to the Kolsky bar and the permanent plate displacement of each test plate. The simulated (maximum) impulse applied to the test plate and maximum transient displacement are also listed.

\begin{tabular}{ccccccc}
\hline $\begin{array}{c}\text { Test } \\
\text { Shot }\end{array}$ & $\begin{array}{c}\text { Experimental } \\
\text { Kolsky bar } \\
\text { impulse } \\
(\mathrm{kPa} \cdot \mathrm{s})\end{array}$ & $\begin{array}{c}\text { Simulated } \\
\text { Kolsky bar } \\
\text { impulse } \\
(\mathrm{kPa} \cdot \mathrm{s})\end{array}$ & $\begin{array}{c}\text { Simulated } \\
\text { predicted } \\
\text { plate impulse } \\
(\mathrm{kPa} \cdot \mathrm{s})\end{array}$ & $\begin{array}{c}\text { Experimental } \\
\text { Z- } \\
\text { displacement } \\
\delta(\mathrm{cm})\end{array}$ & $\begin{array}{c}\text { Simulated } \\
\text { Z- } \\
\text { displacement } \\
\delta(\mathrm{cm})\end{array}$ & $\begin{array}{c}\text { Simulated } \\
\text { max Z- } \\
\text { displacement } \\
\delta_{\max }(\mathrm{cm})\end{array}$ \\
\hline 1 & 12.1 & 11.6 & 15.3 & 4.77 & 4.95 & 5.78 \\
2 & 12.5 & 12.2 & 16.5 & 5.02 & 5.68 & 6.44 \\
3 & 17 & 17.9 & 22.4 & 7.21 & 7.66 & 8.12 \\
4 & 21.5 & 20.7 & 24.2 & 7.84 & 7.92 & 8.64 \\
5 & 21.3 & 22.3 & 25.4 & 8.16 & 8.39 & 8.88 \\
\hline
\end{tabular}

The simulated impulse versus time response at the Kolsky bar strain gauge location is overlaid on the experimental data in Figure 13(d)-(f) and Figure 14(c) and (d). The four regimes identified in the experimental data were clearly present in the simulated data. Table 8 shows the measured and simulated start times for each regime. The simulations were generally in agreement with the measurements. The simulations can therefore be used to investigate the interactions of the later arriving sand particles with the Kolsky bar that cannot be seen in the high-speed videos. 
Table 8. The measured and simulated start times (in microseconds) for each region of the sand loading on the Kolsky bar at the signal arrival time at the strain gauge location (corresponding to impacts at the front of the bar $125 \mu$ s earlier).

\begin{tabular}{|c|c|c|c|c|c|c|c|c|}
\hline \multirow[b]{2}{*}{ Test shot } & \multicolumn{2}{|c|}{ Region I } & \multicolumn{2}{|c|}{ Region II } & \multicolumn{2}{|c|}{ Region III } & \multicolumn{2}{|c|}{ Region IV } \\
\hline & Exp. & Sim. & Exp. & Sim. & Exp. & Sim. & Exp. & Sim. \\
\hline 1 & 350 & 340 & 390 & 395 & 520 & 470 & 545 & 525 \\
\hline 2 & 505 & 500 & 540 & 530 & 710 & 700 & 730 & 760 \\
\hline 3 & 385 & 395 & 420 & 435 & 555 & 565 & 570 & 640 \\
\hline 4 & 600 & 590 & 645 & 630 & 735 & 730 & 760 & 800 \\
\hline 5 & 685 & 700 & 745 & 750 & 855 & 830 & 875 & 920 \\
\hline
\end{tabular}

The Kolsky bar data shows that the range of applied impulses varied from $12.1 \mathrm{kPa} \cdot \mathrm{s}$ (Shot 1) to $21.5 \mathrm{kPa} \cdot \mathrm{s}$ (Shot 4). In general, the data from Shots 1 through 4 indicate the impulse transmitted to the Kolsky bar, and thus (approximately) to the center of the test plates, increased with thickness of the annular region of particles, with explosive mass, and with the density of the granular medium. The measured plateau impulse for Shot 5 was slightly less than that of Shot 4 . However, when the orientation angle of detonation for Shot 5 was decreased from $\theta=70^{\circ}$ to $45^{\circ}$ (as used for the other tests), the impulse to the Kolsky bar was increased by approximately $2 \mathrm{kPa} \cdot \mathrm{s}$. We therefore conclude that an increase in zirconia particle mass, while keeping the explosive core mass fixed, increased the impulse applied to the Kolsky bar. The simulations indicate that the impulse applied to the Kolsky bar was applied by the three particles types (air, HE, and solid glass or zirconia particles), but the majority ( $90 \%)$ of the impulse loading on the Kolsky bar and the test plate originated from impacts by the solid (sand) particles.

\subsection{Panel deformations}

The out of plane (Z-component) displacements of the deformed concave surfaces of the five test plates were measured after testing using a coordinate measuring machine to profile the deformed surface profilometry of the plates in the X-X and $\mathrm{Y}-\mathrm{Y}$ directions. Contour plots of the permanent Z-direction displacements of the test plates are shown for the glass particle tests in Figure 15 (a)-(c) and for the zirconia test shots in Figure 16(a)-(b). The white regions around the border of the contour plots suffered no displacement and surface profile data was therefore not collected for these regions. The simulated displacement contour plots are also shown for comparison in Figure 15(d)-(f) and Figure 16(c)-(d). To aid with comparisons, the contour plots

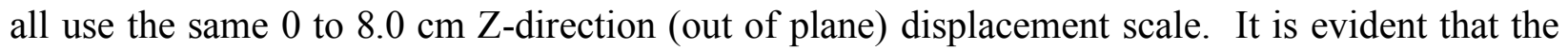
measured and simulated displacement fields are in generally good agreement and that the 
maximum permanent displacement, Table 7 increased from Shot 1-5 (i.e. with incident impulse). The biggest discrepancy between the measured and simulated displacements was observed for Shots 2 and 3 where the simulations slightly over predict the center displacement. The results also reveal that the permanent displacement extended beyond the $81.3 \mathrm{~cm}$ wide central region between the picture frame supports on which the plates were supported. This can be seen more clearly by plotting the measured permanent plate displacement profile along the $\mathrm{X}$-axis (at the $\mathrm{Y}$ - coordinate of maximum $\mathrm{Z}$ displacement) in Figure 17(a) for each of the test charges. Figure 17(b) compares them with the corresponding simulated displacements. Both sets of data confirm that the Zdirection displacement extended outwards beyond the edge of the underlying support structure by a distance that increased with impulse. The maximum permanent displacements of the test plates, $\delta$, are summarized in Table 7 for both experimental and simulation results. The maximum permanent displacement increased from Shot 1 to 5 (with increasing impulse) and exceeded the $2.54 \mathrm{~cm}$ plate thickness for all tests.

While the experimental plate displacement results recorded only the permanent deflection after the test event, the simulations allow analysis of the transient test plate behavior including their damped oscillatory displacement which eventually converged to the permanent displacement. This transient Z-displacement behavior is plotted for each test in Figure 18 for the first $20 \mathrm{~ms}$ following detonation. The maximum dynamic displacement, $\delta_{\max }$, occurred at approximately $2 \mathrm{~ms}$ after detonation, but exceeded the permanent displacement by less than $1 \mathrm{~cm}$ (Table 7). The simulations also enable the specific impulse distribution applied to the test panels to be determined. Figure 19 shows the specific impulse distribution on half sections of the test plates for the five tests arranged by increasing impulse (Shot 1 to Shot 5). The peak specific impulses applied to the test plates for each test shot are summarized in Table 7.

In order for the test plates to undergo the permanent Z-direction displacement shown in Figure 19 , they must also suffer an inplane plastic stretching strain. Since the underlying $81.3 \mathrm{~cm}$ span support structure did not inhibit this stretching, the region that contributed to inplane stretching extended to the edge of the test plates where strong inplane displacement control was imposed. Figure 20(a) shows an example of the final total strain in the Y-direction, $\varepsilon_{Y Y}$, on the plate at 20 $\mathrm{ms}$ after detonation for test Shot 3 . This inplane strain reached a maximum directly above the inner edge of the underlying picture frame support. Three nodes are indicated in Figure 20(a) where the values of the maximum and permanent (after $20 \mathrm{~ms}$ ) displacement magnitude were measured. This 
data is summarized in Table 9 for each test shot along with the final total strain in the Y-direction, $\varepsilon_{Y Y}$, at these node locations. The $\varepsilon_{Y Y}$ strain at these three nodes and their permanent displacements are seen to increase from Shot 1 to 5. The displacements of the nodes indicate the contribution of the edge material stretching to the final permanent shape (displacement profile) of the test plate. The permanent Y-direction displacement of node 3 is also listed in Table 9, which indicates the out of plane displacement near the plate centers was fed by large $\mathrm{X}$ and $\mathrm{Y}$-direction displacements of plate material from outside the central $81.3 \mathrm{~cm}$ panel span. Figure 20(b) shows the effective stress distribution for the same test and indicates that the region which exceeded the yield stress of the plate extended through a significant fraction of the width of the back supported (picture frame shaped) periphery of the test plate.

Table 9. The maximum out of plane dynamic $\left(\delta_{\max }\right)$ and permanent $(\delta)$ displacements and the $\mathrm{Y}$ direction tensile strains at nodes 1, 2, and 3 (Figure 20(a)). The permanent Y displacement $\left(\delta_{Y}\right)$ for node 3 determined at $20 \mathrm{~ms}$ after detonation is also listed.

\begin{tabular}{|c|c|c|c|c|c|c|c|c|c|c|}
\hline \multirow[b]{2}{*}{$\begin{array}{l}\text { Test } \\
\text { shot }\end{array}$} & \multicolumn{3}{|c|}{ Node 1} & \multicolumn{3}{|c|}{ Node 2} & \multicolumn{4}{|c|}{ Node 3} \\
\hline & $\begin{array}{c}\delta_{\max } \\
(\mathrm{mm})\end{array}$ & $\begin{array}{c}\delta \\
(\mathrm{mm}) \\
\end{array}$ & $\varepsilon_{Y Y}$ & $\begin{array}{c}\delta_{\max } \\
(\mathrm{mm})\end{array}$ & $\begin{array}{c}\delta \\
(\mathrm{mm}) \\
\end{array}$ & $\varepsilon_{Y Y}$ & $\begin{array}{c}\delta_{\max } \\
(\mathrm{mm})\end{array}$ & $\begin{array}{c}\delta \\
(\mathrm{mm})\end{array}$ & $\varepsilon_{Y Y}$ & $\begin{array}{c}\delta_{Y} \\
(\mathrm{~mm}) \\
\end{array}$ \\
\hline 1 & 6.21 & 0.23 & 0 & 8.62 & 1.19 & 0.03 & 8.91 & 1.92 & 0.04 & 1.87 \\
\hline 2 & 5.57 & 0.32 & 0 & 7.93 & 1.78 & 0.04 & 9.10 & 2.43 & 0.06 & 2.39 \\
\hline 3 & 6.32 & 0.40 & 0 & 9.09 & 3.04 & 0.06 & 10.09 & 4.15 & 0.08 & 3.96 \\
\hline 4 & 7.27 & 0.45 & 0 & 9.66 & 3.23 & 0.07 & 10.21 & 4.48 & 0.09 & 4.30 \\
\hline 5 & 6.94 & 0.56 & 0 & 9.37 & 3.83 & 0.08 & 9.94 & 5.18 & 0.10 & 4.91 \\
\hline
\end{tabular}

To analyze the effect of increasing impulse on the permanent (plastic) plate deflection, the out of plane deflection was measured (after the test) directly beneath the charge center. This was normalized by both the half span of the unsupported test plate $(2 \mathrm{~L}=81.3 \mathrm{~cm})$ and by that of the edge clamped panel $(2 \mathrm{~L}=122 \mathrm{~cm})$. Both dimensionless displacements are plotted in Figure 21 as a function of the normalized impulse, $I_{o} / m_{b} \sqrt{\sigma_{Y} / \rho_{m}}$. The areal mass of the plate, $m_{b}=\rho_{m} h$ (where $\mathrm{h}$ is the plate thickness $2.54 \mathrm{~cm}$ ) was $200.6 \mathrm{~kg} / \mathrm{m}^{2}$, the plate yield strength, $\sigma_{Y}=310 \mathrm{MPa}$, and the plate material density $\rho_{m}=7900 \mathrm{~kg} / \mathrm{m}^{3}$. The peak specific impulses applied to the test plates were determined from the simulations, Table 7, rather than the Kolsky bar measured impulse (since there was some variation in the standoff distance between the charge and the Kolsky bar/plate during tests). Additional simulations were also conducted at several lower specific impulses to enable observation of the trend as the impulse decreased to zero. Figure 21 shows the permanent out of plane deflection increasing linearly with the incident impulse applied to the 
plates. It also reveals the need for a critical impulse sufficient to cause permanent (plastic) panel deflection. The use of a back supported picture frame-shaped region of the test plates avoided the complications of panel failure in the tests. However, this region was loaded beyond its elastic limit and the resulting inplane plastic displacements permitted a larger deflection of the central, unsupported span.

The momentum transfer between the air and granular particles results in a deceleration of the granular particles, Figure 8(b) and Figure 9(b). To investigate the significance of this momentum transfer mechanism upon the plate's displacement, simulations of each of the test shots were conducted with air particles removed. These displacement results are plotted on Figure 21 (the xdata points), and indicate that removal of air particles does not affect either the impulse or the plates permanent displacement. Conservation of momentum dictates that the sum of the impulse of the air and granular particles must be equal to that of the particles in an air free test. Analysis of the simulations confirmed that the reduction in the granular particle momentum (from that observed without air particles) corresponded to the amount transferred to the air shock. Since the resulting panel displacements were also approximately the same, with or without the presence of air in the simulations, it appears that the effective momentum transfer efficiency to the plates by the two particle types was similar.

\section{Concluding remarks}

The deformation of edge restrained and partially back supported stainless steel plates has been investigated following impact by high velocity, spherically symmetric granular material shells using a combination of large-scale experiments and numerical simulations implemented in the discrete particle-based IMPETUS Afea code. The study used suspended spherical explosive charges to accelerate 25 to $150 \mathrm{~kg}$ spherical shells of water saturated glass or higher density zirconia particles to velocities of 500-1200 m/s. The evolution of the granular shell topology following detonation was experimentally characterized by analysis of high-speed video images. This data revealed that the radial velocity of the granular particles reached a maximum within a short distance of the original location of the particles, and then slowly decreased with radial distance due to momentum transfer from the particles to the background air. The high-speed video images also revealed the presence of a "particle finger-like" instability at the expanding granular shell - air interface. Its presence was consistent with a recent analysis by Kandan et al. [42] of the 
interaction of supersonic granular particles with a high-pressure air shocks. The instability was most prominent at the leading edge of the fastest expanding granular shells, in agreement with the recent analysis.

The test charges were positioned above the center of $2.54 \mathrm{~cm}$ thick edge clamped $1.32 \mathrm{~m} \mathrm{x}$ $1.32 \mathrm{~m}$ panels made of high ductility, 304 stainless steel, and their permanent deflection fields were measured after testing. A novel edge restraint approach was utilized to avoid disruption of reflected particle flow over the impacted surface of the sample. Unobstructed out of plane displacement of the plate was permitted within a central $81.3 \mathrm{~cm}$ by $81.3 \mathrm{~cm}$ square opening of the panel. While this gripping approach avoided plate failure near the gripped regions, the $20.3 \mathrm{~cm}$ wide picture frame region between the central opening and the outer edge gripped periphery of the test plates was loaded beyond its elastic limit and contributed an inplane stretching displacement that increased the out of plane deflections.

A Kolsky bar positioned at a location that sampled an impulsive load equivalent to that at the plate center was used to measure both the pressure and specific impulse applied to the plate center. The expansion of the granular shells, as well as the pressure and impulse transferred to the Kolsky bar were all well predicted by the discrete particle-based simulation approach. It also provided insight into the mechanisms of target loading in the region behind the particle front where direct observation with the high-speed cameras was obscured by particles and high explosive reaction product gases. The IMPETUS Afea code was used to simulate the impulse distribution applied to the test plates and successfully predicted the test plates out of plane displacement distribution and enabled interpretation of the factors that governed this behavior. The study confirms earlier, simplified model estimates for the approximately linear dependence of the out of plane displacement of edge clamped plates upon incident specific impulse.

\section{Acknowledgements}

The authors are grateful for the experimental assistance and guidance provided by Tommy Eanes. The funding for this research was provided by the Defense Advanced Research Projects Agency (DARPA) under grant number W91CRB-11-1-0005 (Program manager, Dr. J. Goldwasser). 


\section{Appendix A}

Upon detonation, a shock front propagates through the high explosive (HE) particles until reaching the interface between the $\mathrm{HE}$ and sand particles. A compressive shock is then launched into the wet sand and the shock propagates outward until reaching the outer surface of the test charge, thus breaking the acrylic shell. These shock propagations are shown for each test charge in Figure A1 (Shots 1-3) and Figure A2 (Shots 4 and 5). The acrylic shell is not shown in these images. The white dotted lines indicate the location of the detonation shock in the HE particles, and the black dotted lines mark the location of the compressive shock in the wet sand region. The changes in the inner and outer shell diameters can be seen for the different charge configurations. These changes influence the shock propagation time and thus the time for the outer acrylic shell to break. The propagation times were consistent with a C4 detonation velocity of $8190 \mathrm{~m} / \mathrm{s}$ defined in the solver, $3600 \mathrm{~m} / \mathrm{s}$ shock speed in the wet synthetic (glass particle) sand and $3100 \mathrm{~m} / \mathrm{s} \mathrm{shock}$ speed in a wet zirconia particle aggregate consistent with reported velocities for shock propagation in water saturated granular media $[44,45]$. These simulation times correlate with the times calculated in Table 3 where a handbook detonation velocity of $8040 \mathrm{~m} / \mathrm{s}$ [46] was used to estimate the detonation wave propagation time. 


\section{References}

[1] W. Fourney, U. Leiste, R. Bonenberger, D. Goodings, Explosive impulse on plates, Fragblast, 9 (2005) 1-17.

[2] A. Ramasamy, A.-M. Hill, A. Hepper, A.M. Bull, J. Clasper, Blast mines: physics, injury mechanisms and vehicle protection, Journal of the Royal Army Medical Corps, 155 (2009) 258-264.

[3] A. Neuberger, S. Peles, D. Rittel, Scaling the response of circular plates subjected to large and closerange spherical explosions. Part II: buried charges, International journal of impact engineering, 34 (2007) 874-882.

[4] S. Kiefl'er, Blast dynamics at Mount St. Helens on 18 May 1980, Nature, 291 (1981) 568-570.

[5] I.A. Nairn, Atmospheric shock waves and condensation clouds from Ngauruhoe explosive eruptions, Nature, 259 (1976) 190-192.

[6] L. Wilson, Explosive volcanic eruptions-II The atmospheric trajectories of pyroclasts, Geophysical Journal International, 30 (1972) 381-392.

[7] D.M. Bergeron, R. Walker, C. Coffey, Detonation of 100-gram Anti-personnel Mine Surrogate Charges in Sand, a Test Case for Computer Code Validation, National Defence, Defence Research Establishment Suffield, 1998.

[8] D. Frost, C. Ornthanalai, Z. Zarei, V. Tanguay, F. Zhang, Particle momentum effects from the detonation of heterogeneous explosives, Journal of Applied Physics, 101 (2007) 113529.

[9] F. Zhang, D. Frost, P. Thibault, S. Murray, Explosive dispersal of solid particles, Shock Waves, 10 (2001) 431-443.

[10] R.L. Holloman, V. Deshpande, H.N.G. Wadley, Impulse transfer during sand impact with a solid block, International journal of impact engineering, 76 (2015) 98-117.

[11] A. Kyner, K. Dharmasena, K. Williams, V.S. Deshpande, H.N.G. Wadley, High intensity impulsive loading by explosively accelerated granular matter, International journal of impact engineering, 108 (2017) 229-251.

[12] H.N. Wadley, T. Børvik, L. Olovsson, J.J. Wetzel, K.P. Dharmasena, O.S. Hopperstad, V. Deshpande, J.W. Hutchinson, Deformation and fracture of impulsively loaded sandwich panels, Journal of the Mechanics and Physics of Solids, 61 (2013) 674-699.

[13] G. Nurick, G. Shave, The deformation and tearing of thin square plates subjected to impulsive loads - an experimental study, International journal of impact engineering, 18 (1996) 99-116.

[14] M. Olson, G. Nurick, J. Fagnan, Deformation and rupture of blast loaded square plates-predictions and experiments, International journal of impact engineering, 13 (1993) 279-291.

[15] E.G. Pickering, S.C.K. Yuen, G. Nurick, P. Haw, The response of quadrangular plates to buried charges, International journal of impact engineering, 49 (2012) 103-114.

[16] D. Fox, X. Huang, D. Jung, W. Fourney, U. Leiste, J. Lee, The response of small scale rigid targets to shallow buried explosive detonations, International journal of impact engineering, 38 (2011) 882-891.

[17] K.P. Dharmasena, H.N. Wadley, T. Liu, V.S. Deshpande, The dynamic response of edge clamped plates loaded by spherically expanding sand shells, International journal of impact engineering, 62 (2013) 182-195.

[18] W. Fourney, U. Leiste, R. Bonenberger, D. Goodings, Mechanism of loading on plates due to explosive detonation, Fragblast, 9 (2005) 205-217.

[19] T. Liu, N. Fleck, H. Wadley, V. Deshpande, The impact of sand slugs against beams and plates: Coupled discrete particle/finite element simulations, Journal of the Mechanics and Physics of Solids, 61 (2013) 1798-1821.

[20] S. Park, T. Uth, N. Fleck, H. Wadley, V. Deshpande, Sand column impact onto a Kolsky pressure bar, International journal of impact engineering, 62 (2013) 229-242. 
[21] S. Pingle, N. Fleck, H. Wadley, V. Deshpande, Discrete element calculations of the impact of a sand column against rigid structures, International journal of impact engineering, 45 (2012) 74-89.

[22] M. Glauert, The wall jet, Journal of Fluid Mechanics, 1 (1956) 625-643.

[23] R.L. Holloman, V. Deshpande, H.N.G. Wadley, Impulse transfer during sand impact with a cellular structure, International journal of impact engineering, 82 (2015) 36-58.

[24] G. Taylor, The pressure and impulse of submarine explosion waves on plates, The scientific papers of GI Taylor, 3 (1963) 287-303.

[25] Z. Wei, K. Dharmasena, H. Wadley, A. Evans, Analysis and interpretation of a test for characterizing the response of sandwich panels to water blast, International journal of impact engineering, 34 (2007) $1602-1618$.

[26] G. Nurick, M. Gelman, N. Marshall, Tearing of blast loaded plates with clamped boundary conditions, International journal of impact engineering, 18 (1996) 803-827.

[27] S. Mendes, H. Opat, Tearing and shear failures in explosively loaded clamped beams, Exp. Mech, 13 (1973) 480-486.

[28] R. Davies, A critical study of the Hopkinson pressure bar, Philosophical Transactions of the Royal Society of London A: Mathematical, Physical and Engineering Sciences, 240 (1948) 375-457.

[29] E. Davies, S. Hunter, The dynamic compression testing of solids by the method of the split Hopkinson pressure bar, Journal of the Mechanics and Physics of Solids, 11 (1963) 155-179.

[30] H. Kolsky, Stress waves in solids, Clarendon, in, Oxford, 1953.

[31] B. Hopkinson, A method of measuring the pressure produced in the detonation of high explosives or by the impact of bullets, Philosophical Transactions of the Royal Society of London. Series A, Containing Papers of a Mathematical or Physical Character, 213 (1914) 437-456.

[32] L. Olovsson, A.G. Hanssen, T. Børvik, M. Langseth, A particle-based approach to close-range blast loading, European Journal of Mechanics - A/Solids, 29 (2010) 1-6.

[33] V. Deshpande, R. McMeeking, H. Wadley, A. Evans, Constitutive model for predicting dynamic interactions between soil ejecta and structural panels, Journal of the Mechanics and Physics of Solids, 57 (2009) 1139-1164.

[34] T. Børvik, L. Olovsson, A. Hanssen, K. Dharmasena, H. Hansson, H. Wadley, A discrete particle approach to simulate the combined effect of blast and sand impact loading of steel plates, Journal of the Mechanics and Physics of Solids, 59 (2011) 940-958.

[35] J.A. Simmons, E. Drescher-Krasicka, H. Wadley, Leaky axisymmetric modes in infinite clad rods. I, The Journal of the Acoustical Society of America, 92 (1992) 1061-1090.

[36] J. Dean, C. Dunleavy, P. Brown, T. Clyne, Energy absorption during projectile perforation of thin steel plates and the kinetic energy of ejected fragments, International journal of impact engineering, 36 (2009) 1250-1258.

[37] L. Mori, S. Lee, Z. Xue, A. Vaziri, D. Queheillalt, K. Dharmasena, H. Wadley, J. Hutchinson, H. Espinosa, Deformation and fracture modes of sandwich structures subjected to underwater impulsive loads, Journal of mechanics of materials and structures, 2 (2007) 1981-2006.

[38] E.L. Guzas, C.J. Earls, Simulating blast effects on steel beam-column members: Methods, Computers \& Structures, 89 (2011) 2133-2148.

[39] J.D. Cinnamon, A.N. Palazotto, Z. Kennan, Material characterization and development of a constitutive relationship for hypervelocity impact of 1080 Steel and VascoMax 300, International journal of impact engineering, 33 (2006) 180-189.

[40] U.K. Viswanathan, R. Kishore, M.K. Asundi, Effect of thermal cycling on the mechanical properties of 350-grade maraging steel, MMTA, 27 (1996) 757-761.

[41] G. Cohen, P. Gilles, S. Segonds, M. Mousseigne, P. Lagarrigue, Thermal and mechanical modeling during dry turning operations, The International Journal of Advanced Manufacturing Technology, 58 (2012) 133-140. 
[42] K. Kandan, S. Khaderi, H.N.G. Wadley, V.S. Deshpande, Instabilities in shock loaded granular media, In progress, (2016).

[43] A.D. Puckett, M. Peterson, Individual longitudinal Pochhammer-Chree modes in observed experimental signals, Acoustics Research Letters Online, 6 (2005) 268-273.

[44] M. Prasad, M. Zimmer, P. Berge, B. Bonner, Laboratory measurements of velocity and attenuation in sediments, University of California, Lawrence Livermore National Laboratory, Report, 205155 (2004). [45] D. Chapman, K. Tsembelis, W. Proud, The behavior of water saturated sand under shock-loading, in: Proceedings of the 2006 SEM Annual Conference and Exposition on Experimental and applied mechanics, 2006, pp. 834-840.

[46] M. Explosives, Department of the Army Technical Manual, in, TM 9-1300-214, September, 1984. 


\section{Figure Captions}

Figure 1. (a) Monolithic (solid) plate impacted by a sand slug with incident impulse, $I_{o}$. (b) Discrete particle predictions of the dimensionless maximum (elastic plus plastic) dynamic deflection of an edge clamped plate versus dimensionless impulse for collimated sand slug impacts at a $90^{\circ}$ angle of incidence. (Adapted from Liu et al. [19])

Figure 2. (a) The experimental setup showing test plate and suspended charge location together with the strain gage instrumented Kolsky bar. (b) A side view of the test arrangement showing the position of the Kolsky bar and test plate at similar distances and orientations to the test charge.

Figure 3. Schematic illustration showing explosive charge, detonator, and Kolsky bar placement relative to test panel. Each test panel had a $5.1 \mathrm{~cm}$ wide perimeter lip to provide edge restraint.

Figure 4. Optical image of the (a) fused silica and (b) zirconia particles used for experimental testing.

Figure 5. Simulation model of test setup with suspended test charge above an edge clamped test plate with a Kolsky bar positioned to measure the applied pressure and impulse loading.

Figure 6. High-speed video images of glass microsphere tests. (a) Shot 1 (R1 = $80 \mathrm{~mm}$; R2 = 152 $\mathrm{mm} ; 3 \mathrm{~kg}$ charge) (b) Shot $2(\mathrm{R} 1=80 \mathrm{~mm} ; \mathrm{R} 2=203 \mathrm{~mm} ; 3 \mathrm{~kg}$ charge) and (c) Shot $3(\mathrm{R} 1=90$ $\mathrm{mm} ; \mathrm{R} 2=203 \mathrm{~mm} ; 4.5 \mathrm{~kg}$ charge). The insets in (c), (f) and (i) show "sand fingers" emanating from the main sand fronts.

Figure 7. High speed video images from the zirconia particle tests. (a) R1 $=90 \mathrm{~mm}$; R2 $=203 \mathrm{~mm}$; $4.5 \mathrm{~kg}$ charge (b) R1 $=90 \mathrm{~mm} ; \mathrm{R} 2=229 \mathrm{~mm} ; 4.5 \mathrm{~kg}$ charge. The insets in (c) and (f) indicate little particle finger formation emanating from the main particle front.

Figure 8. (a) Particle position and (b) main particle front velocity versus time for the glass microsphere test configurations (Shots 1-3). In (a) the filled in markers represent the experimental results and the empty markers are from the simulations.

Figure 9. (a) Particle position and (b) sand front velocity versus time for the zirconia test configurations (Shots 4 and 5). In (a) the filled in markers represent the experimental results and the empty markers those from the simulation.

Figure 10. Simulation of particle positions for the three glass microsphere tests at times $\mathrm{t}=0 \mathrm{~s}, \mathrm{t}=$ $250 \mu \mathrm{s}$, and $650 \mu \mathrm{s}$. The model is section cut through the center of each test plate.

Figure 11. Simulation of particle positions for the zirconia particle tests. (a) Shot 4 and (b) Shot 5 at times $\mathrm{t}=0 \mathrm{~s}, \mathrm{t}=250 \mu \mathrm{s}$, and $650 \mu \mathrm{s}$. The model is section cut along the center of each test plate.

Figure 12. High-speed video images showing the air shock that developed in front of the expanding sand shell for Shot 2 (a) $t=333 \mu$ s and (b) $t=555 \mu$ s after detonation. The insets use a dashed white line to indicate the position of expanding air shock ahead of the particles. Simulation images are shown at approximately equivalent times in (c) at $t=330 \mu \mathrm{s}$ and in (d) at $\mathrm{t}=550 \mu \mathrm{s}$ after detonation. The blue dots are air particles, and the region of concentration ahead of the expanding 
particle front corresponds to the shock. The black line on the Kolsky bar in (c) and (d) indicates the $10 \mathrm{~cm}$ length painted region of the Kolsky bar in the high-speed video image in (a).

Figure 13. Kolsky bar data for the three glass microsphere tests. The waveforms in (a), (b) and (c) show the pressure measured at the strain gage location for Shots 1, 2 and 3. Figures (d), (e) and (f) show the impulse (measured and simulated) for test Shots 1, 2 and 3.

Figure 14. Kolsky bar data for the two zirconia tests (Shots 4 and 5). The waveforms in (a) and (b) show the pressure versus time response measured at the stain gage location for Shots 4 and 5 . The corresponding impulses (measured and simulated) are given in (c) and (d).

Figure 15. Test plate out of plane displacement contour plots for the glass particle tests (Shots 1, 2 and 3). Experimental profilometry results are shown in (a), (b) and (c). The simulated responses at $\mathrm{t}=20 \mathrm{~ms}$ after plate oscillations had decayed to an approximate steady state displacement are shown in (d), (e) and (f). The white dashed lines indicate the location of the underlying support structure. Within this region, the panels were not back supported.

Figure 16. Out of plane displacement contour plots for the zirconia tests (Shots 4 and 5). Experimental results are shown in (a) and (b) while the simulated responses after the plate oscillations had decayed to an approximate steady state $(\mathrm{t}=20 \mathrm{~ms})$ are shown in (c) and (d). The white dashed lines indicate the outline of the underlying support structure.

Figure 17. Mid-section out of plane deflection profiles for the five test panels. (a) Measured and (b) simulated results.

Figure 18. Simulated transient out of plane deflection at the center of the test plates impacted by each test charge.

Figure 19. The simulated specific impulse distribution applied to the test plates for the five test charge configurations. The maximum deflection $(\delta)$ is also shown for each test and the $81.3 \mathrm{~cm}$ wide region where no back support of the panels was provided.

Figure 20. (a) The simulated test plate total strain in the y-direction for Shot 3 at $20 \mathrm{~ms}$ after detonation. The samples were edge restrained by the picture frame support (with a span of 122 $\mathrm{cm}$ ). The inner, $81.3 \mathrm{~cm}$ wide center of the panels was not back supported allowing unconstrained out of plane deflection as well as in-plane stretching. The outer $20.35 \mathrm{~cm}$ wide picture frame provided rigid back support of the panels but did not restrain in-plane stretching. Three node locations are indicated where the nodal strain and displacement magnitude were recorded for each test shot. (b) The effective stress for Shot 3 at $1 \mathrm{~ms}$ after detonation showing regions of the plate that that were stressed beyond the yield strength $(310 \mathrm{MPa})$ of the plate material.

Figure 21. The simulated permanent plate deflection scaled by the half span, L versus dimensionless impulse in which $I_{o}$ corresponded to the maximum simulated specific impulse applied near the test plate centers. Results are shown for the $81.3 \mathrm{~cm}$ wide span where no back support existed (open circles) and the $122 \mathrm{~cm}$ span over which unconstrained in-plane panel stretching was allowed (open squares). The experimentally measured deflections normalized by the two span lengths are also shown (solid circle and solid square data). The $\mathrm{x}$ data points correspond to simulations in which the background air particles were omitted. 
Figure A1. Simulated results showing shock front propagation through the three glass particle charges (Shots 1-3). The dashed white line in (j) shows the approximate location of the detonation front in the explosive while the dashed black lines show the position of the wet sand shock fronts.

Figure A2. Simulated results showing shock front propagation through the two water saturated zirconia charges (Shots 4 and 5). The dashed white line shows the approximate location of the detonation front in the explosive while the dashed black line shows the shock front locations in the granular media at various times after detonation. 
(a)
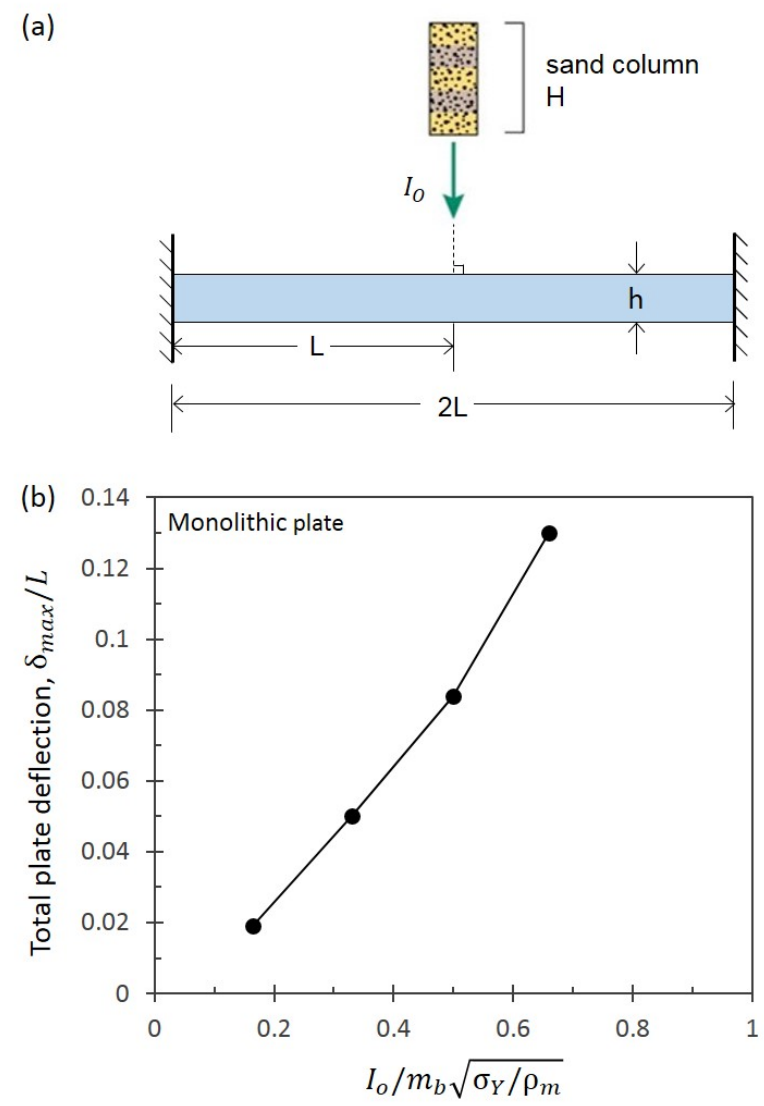

Figure 1. (a) Monolithic (solid) plate impacted by a sand slug with incident impulse, $I_{o}$. (b) Discrete particle predictions of the dimensionless maximum (elastic plus plastic) dynamic deflection of an edge clamped plate versus dimensionless impulse for collimated sand slug impacts at a $90^{\circ}$ angle of incidence. (Adapted from Liu et al. [19]) 
(a)

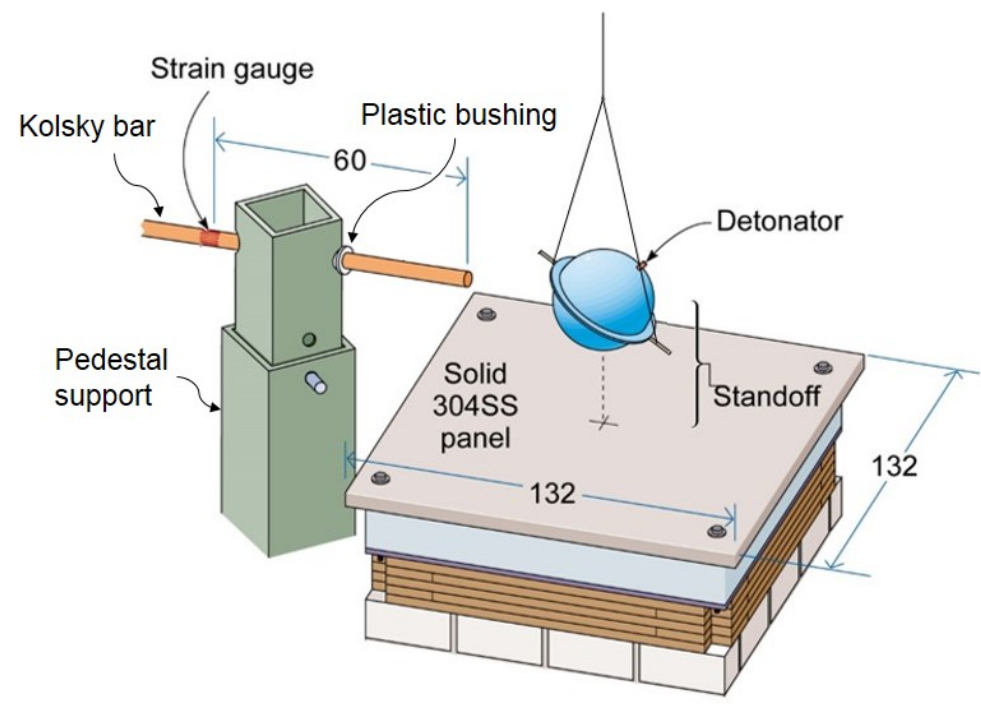

(b)

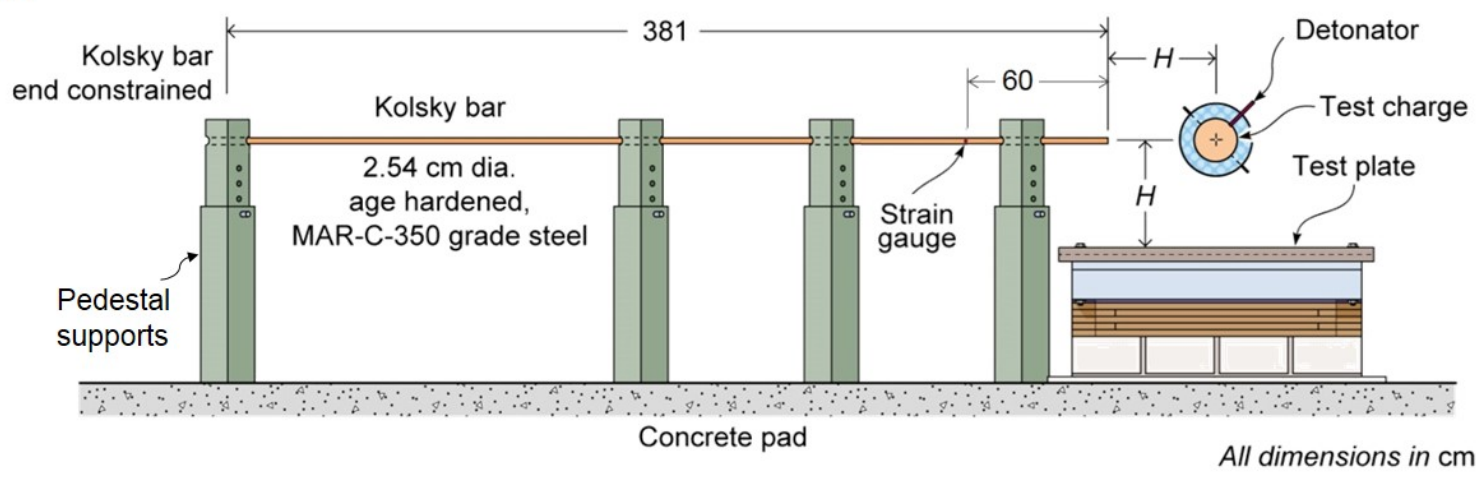

Figure 2. (a) The experimental setup showing test plate and suspended charge location together with the strain gage instrumented Kolsky bar. (b) A side view of the test arrangement showing the position of the Kolsky bar and test plate at similar distances and orientations to the test charge. 


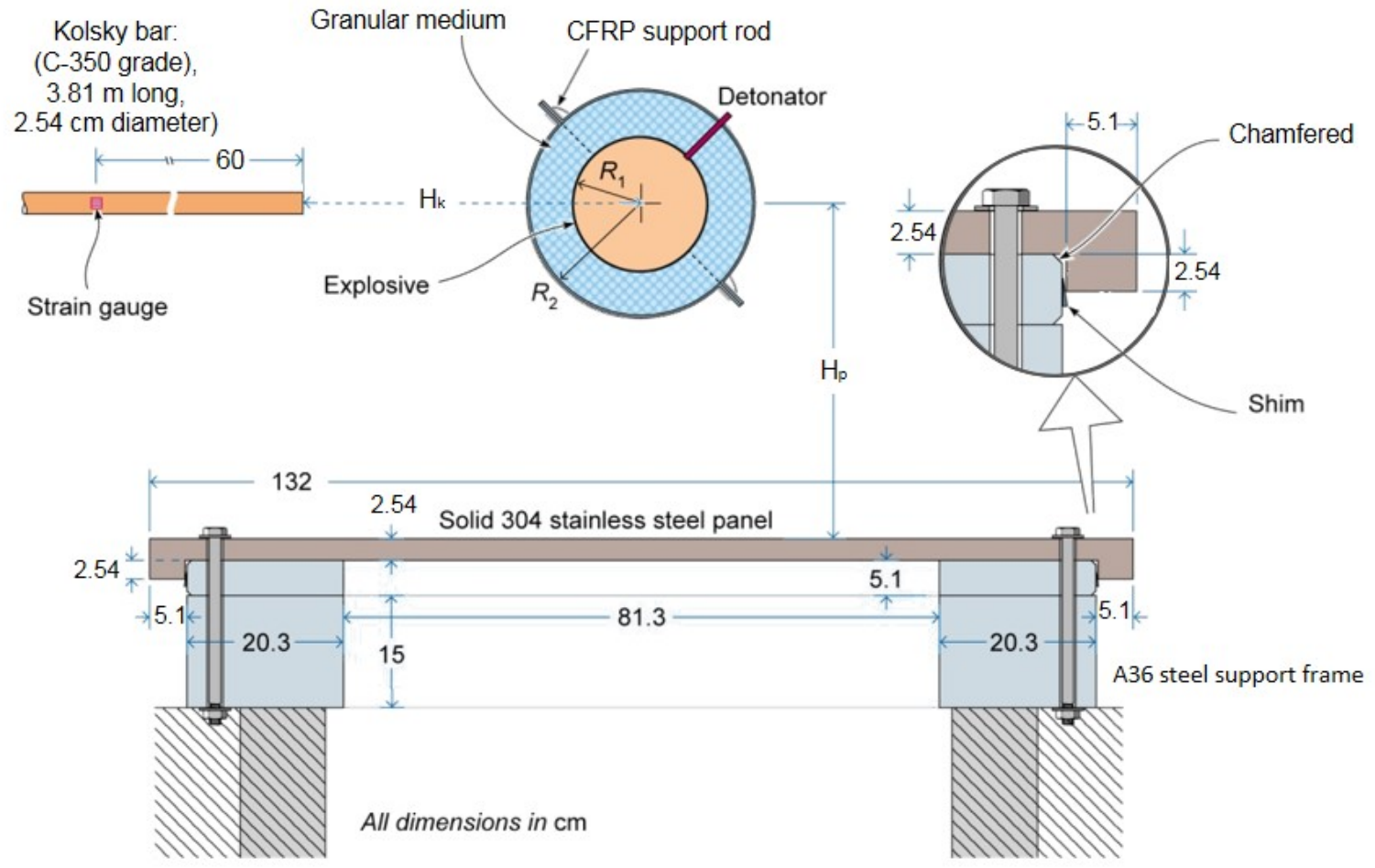

Figure 3. Schematic illustration showing explosive charge, detonator, and Kolsky bar placement relative to test panel. Each test panel had a $5.1 \mathrm{~cm}$ wide perimeter lip to provide edge restraint. 

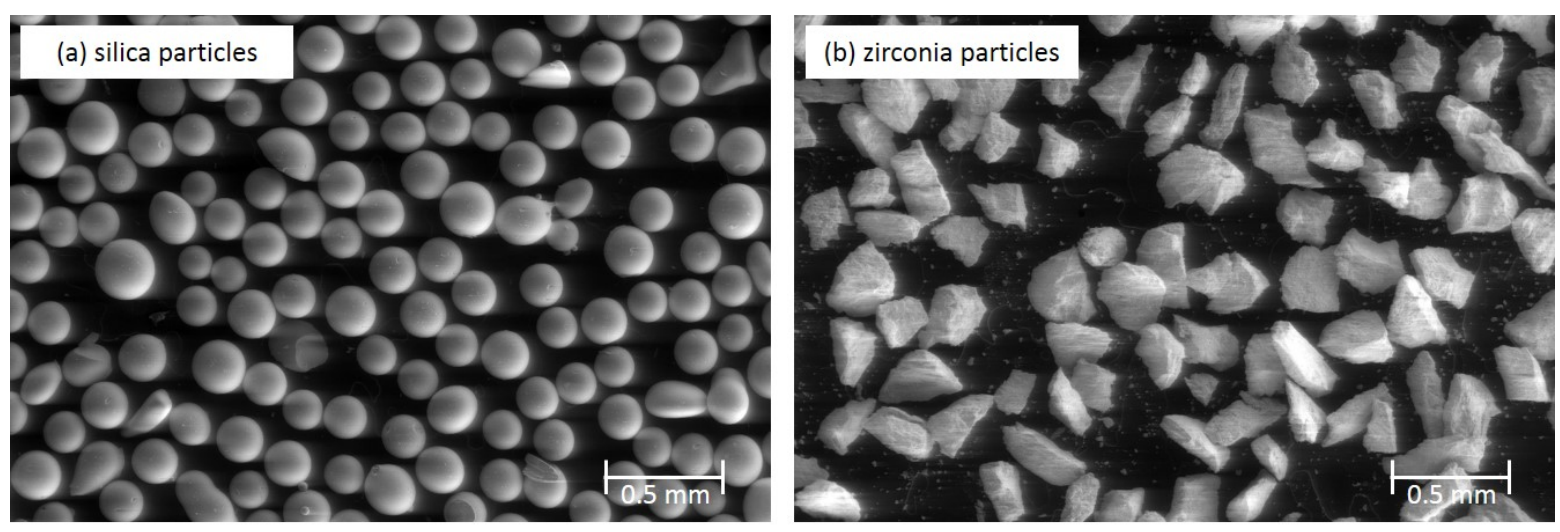

Figure 4. Optical image of the (a) fused silica and (b) zirconia particles used for experimental testing. 


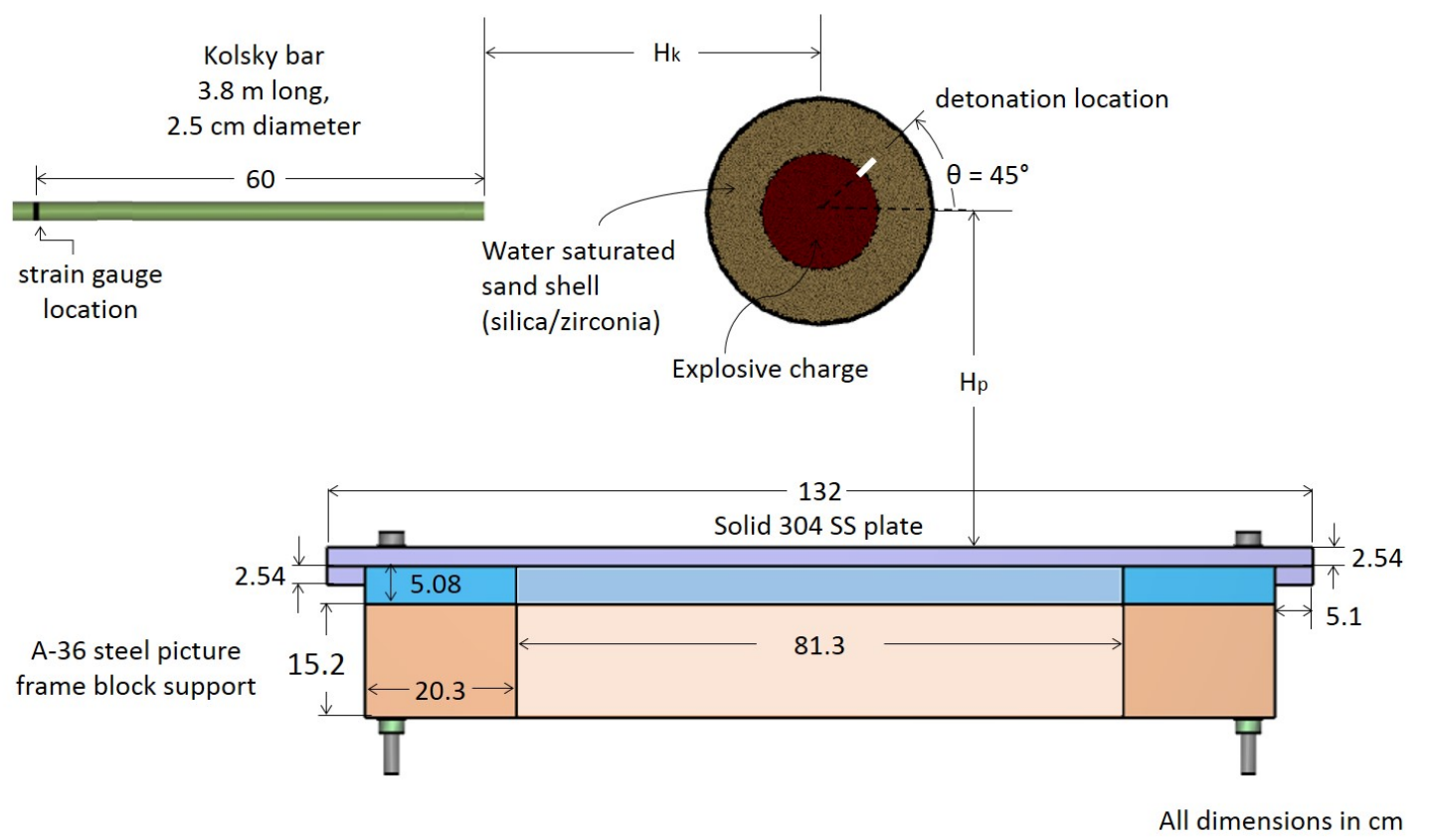

Figure 5. Simulation model of test setup with suspended test charge above an edge clamped test plate with a Kolsky bar positioned to measure the applied pressure and impulse loading. 
Shot 1: $(80,152)$; silica
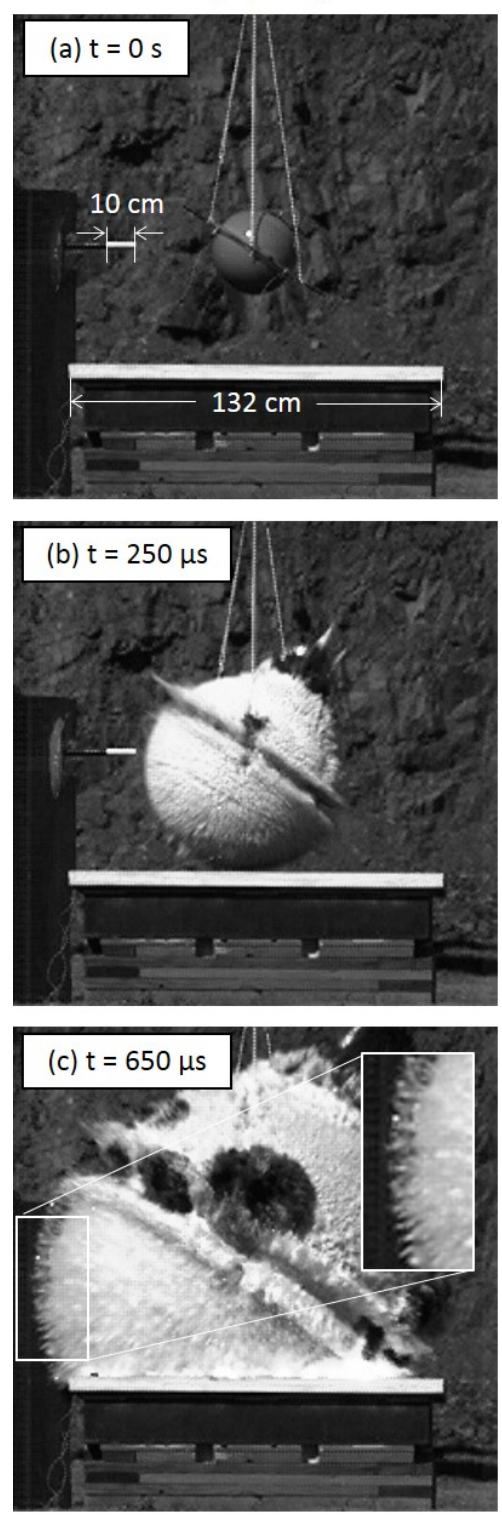

Shot 2: $(80,203)$; silica
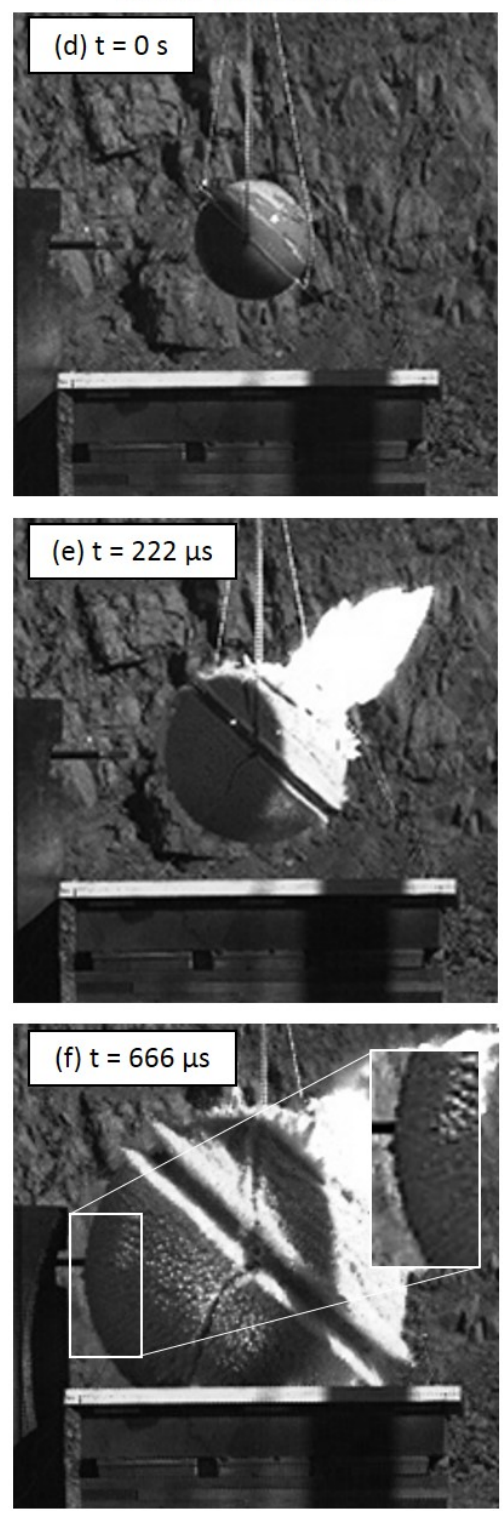

Shot 3: $(90,203)$; silica
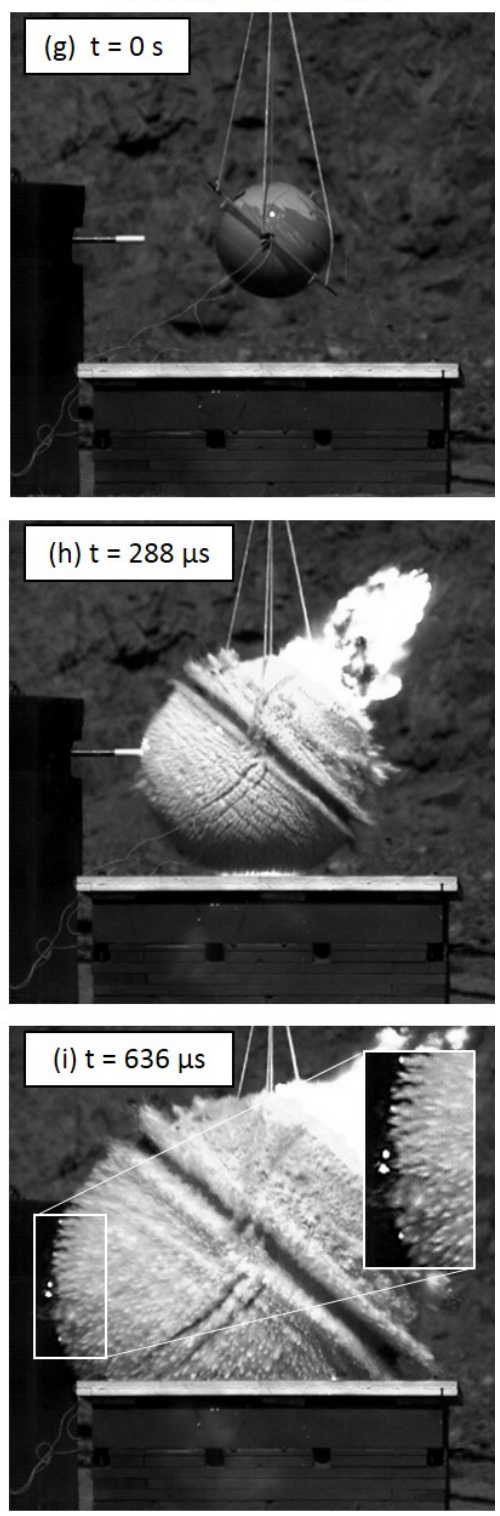

Figure 6. High-speed video images of glass microsphere tests. (a) Shot 1 (R1 = $80 \mathrm{~mm}$; R2 = 152 $\mathrm{mm} ; 3 \mathrm{~kg}$ charge) (b) Shot $2(\mathrm{R} 1=80 \mathrm{~mm} ; \mathrm{R} 2=203 \mathrm{~mm} ; 3 \mathrm{~kg}$ charge) and (c) Shot 3 (R1 = 90 $\mathrm{mm} ; \mathrm{R} 2=203 \mathrm{~mm} ; 4.5 \mathrm{~kg}$ charge). The insets in (c), (f) and (i) show "sand fingers" emanating from the main sand fronts. 
Shot 4: $(90,203)$; zirconia
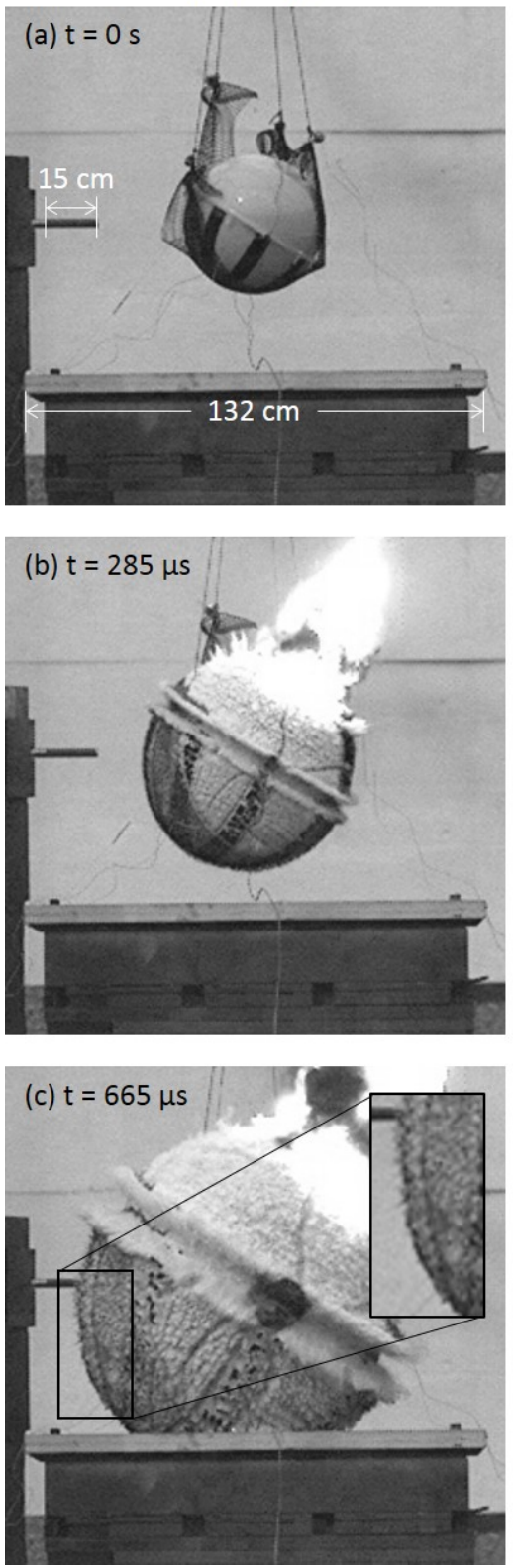

Shot 5: $(90,229)$; zirconia
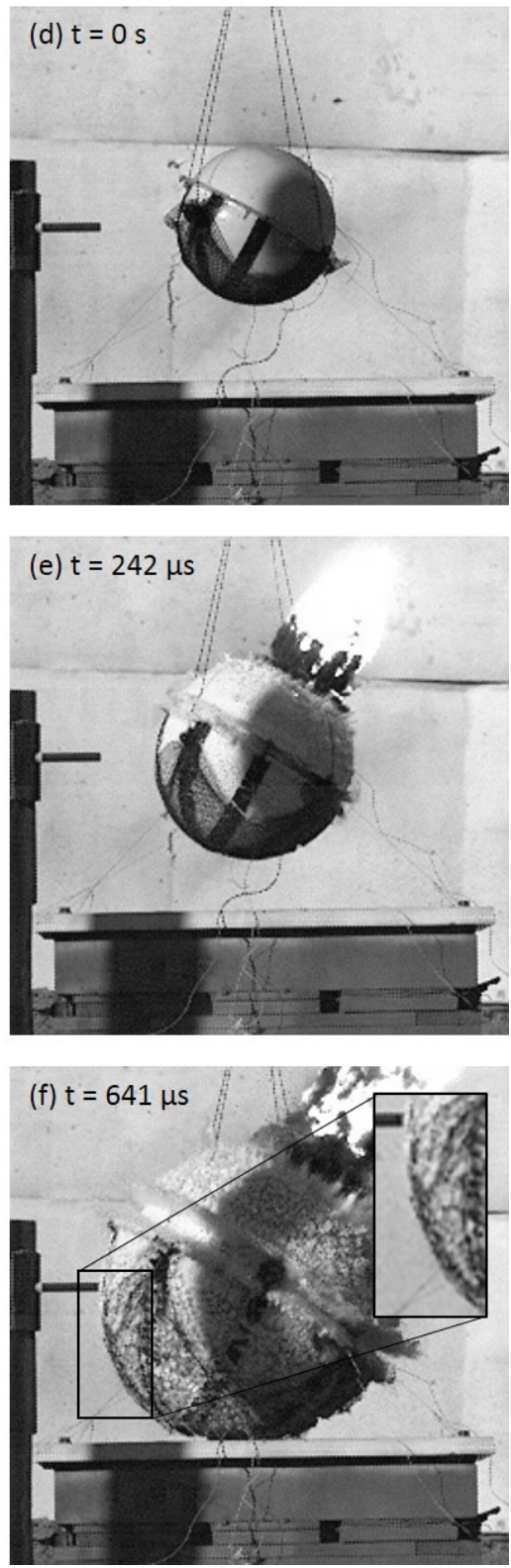

Figure 7. High speed video images from the zirconia particle tests. (a) R1 $=90 \mathrm{~mm}$; R2 $=203$ $\mathrm{mm} ; 4.5 \mathrm{~kg}$ charge (b) R1 $=90 \mathrm{~mm}$; $2=229 \mathrm{~mm} ; 4.5 \mathrm{~kg}$ charge. The insets in (c) and (f) indicate little particle finger formation emanating from the main particle front. 

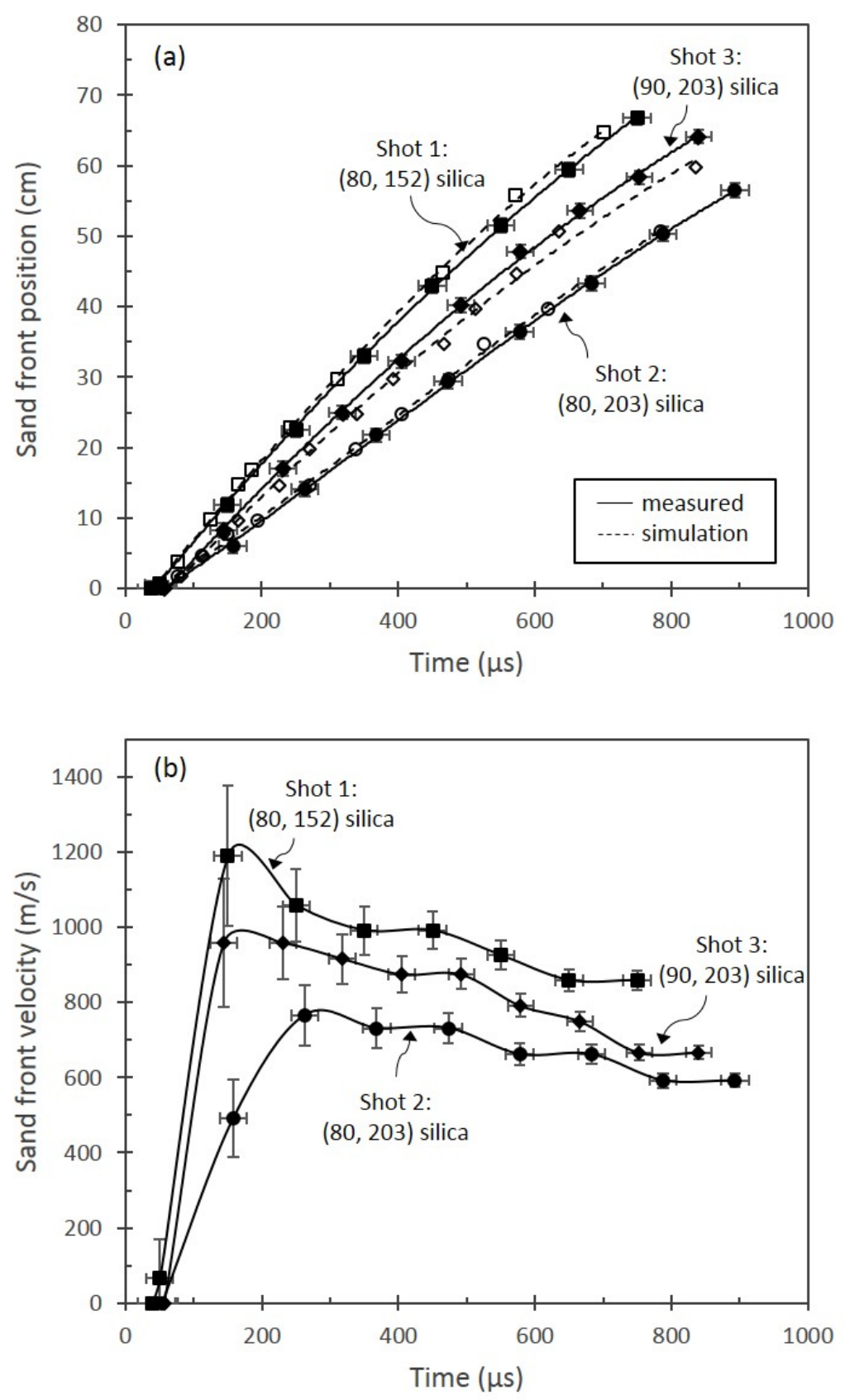

Figure 8. (a) Particle position and (b) main particle front velocity versus time for the glass microsphere test configurations (Shots 1-3). In (a) the filled in markers represent the experimental results and the empty markers are from the simulations. 

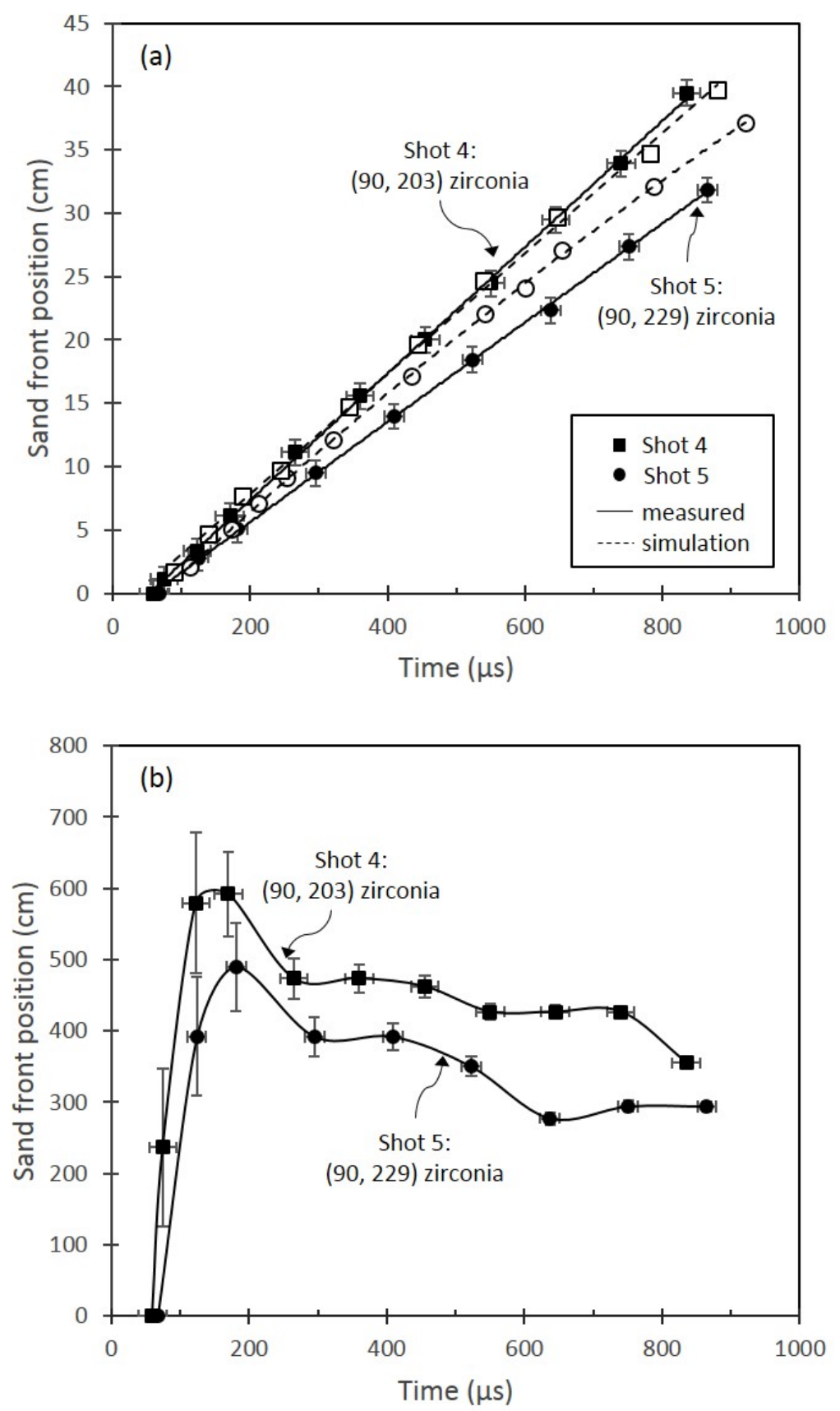

Figure 9. (a) Particle position and (b) sand front velocity versus time for the zirconia test configurations (Shots 4 and 5). In (a) the filled in markers represent the experimental results and the empty markers those from the simulation. 

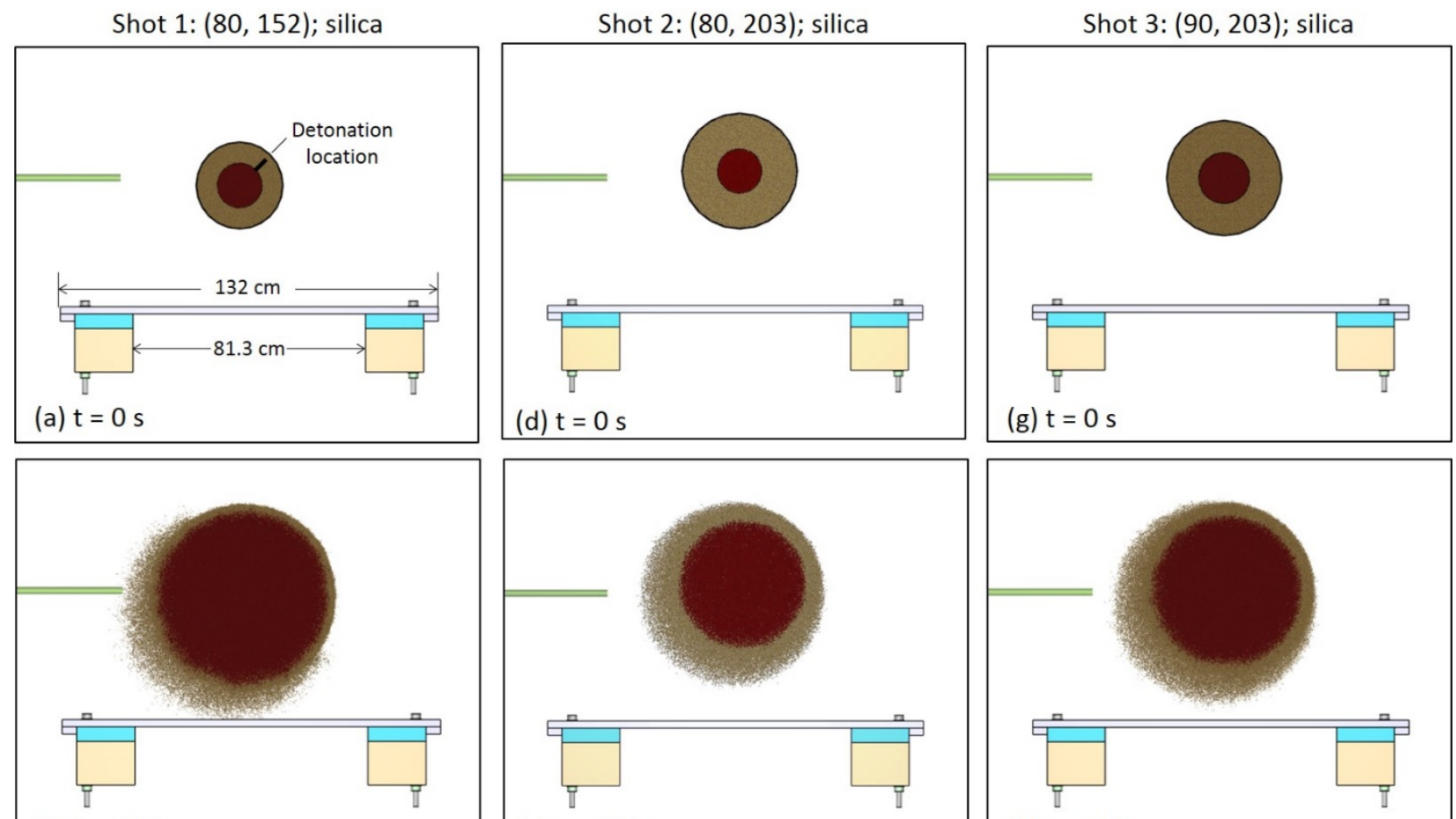

(b) $\mathrm{t}=250 \mu \mathrm{s}$
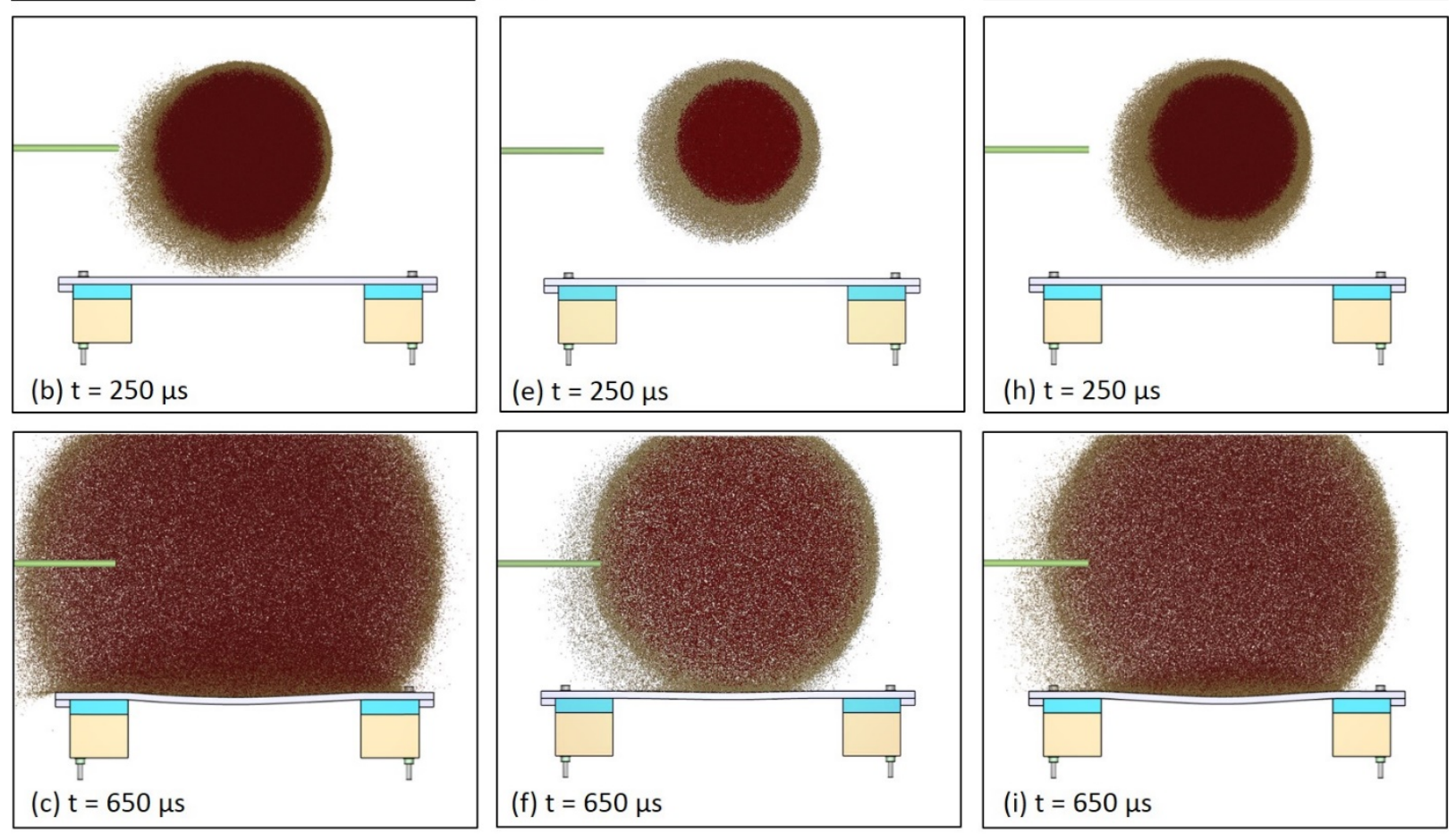

Figure 10. Simulation of particle positions for the three glass microsphere tests at times $t=0 \mathrm{~s}, \mathrm{t}$ $=250 \mu \mathrm{s}$, and $650 \mu \mathrm{s}$. The model is section cut through the center of each test plate. 
Shot 4: $(90,203)$; zirconia
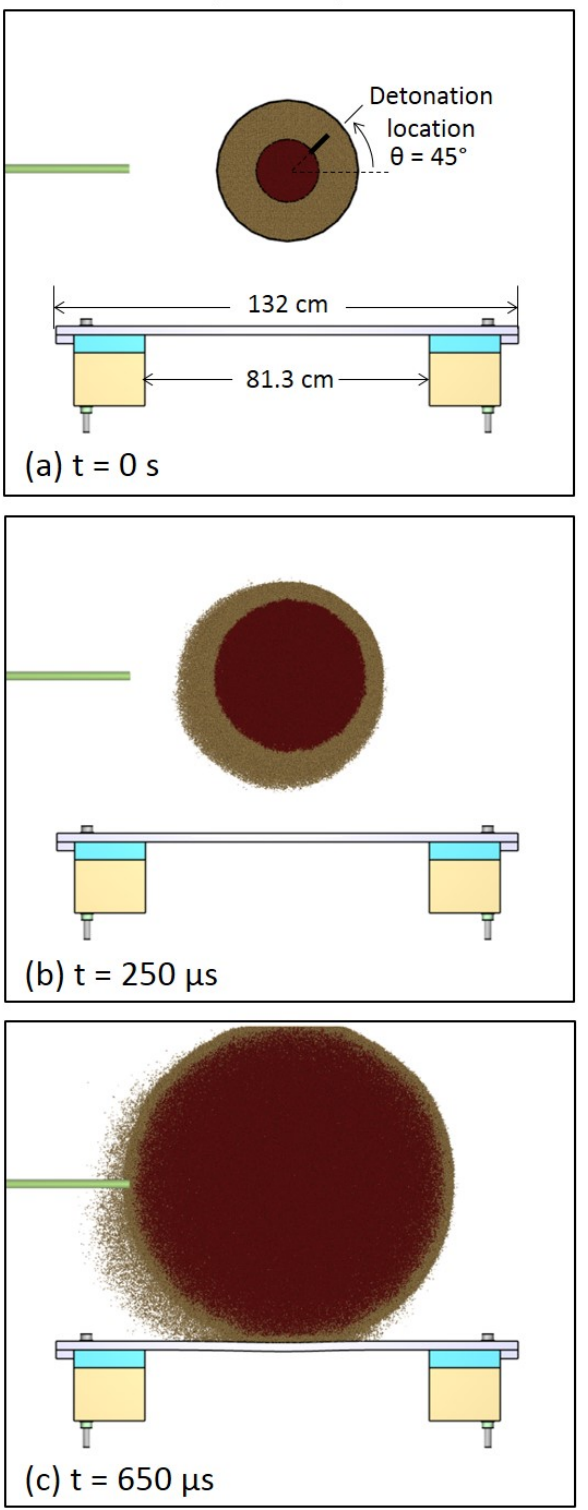

Shot 5: (90, 229); zirconia
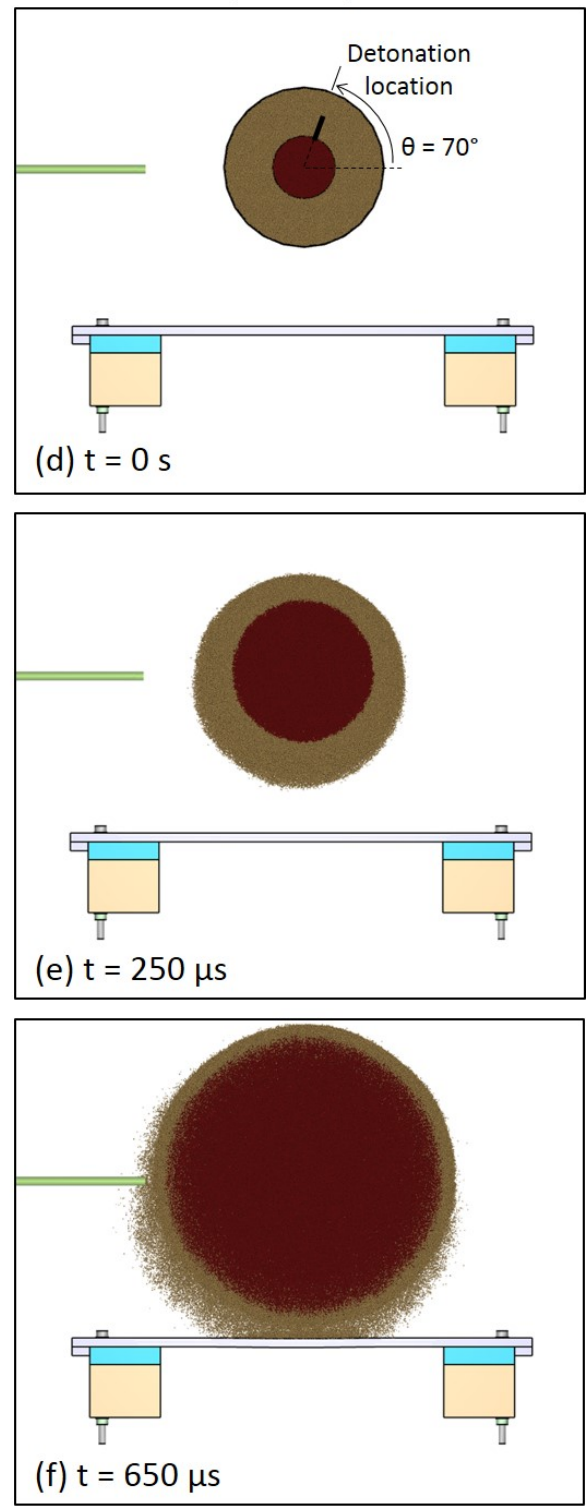

Figure 11. Simulation of particle positions for the zirconia particle tests. (a) Shot 4 and (b) Shot 5 at times $\mathrm{t}=0 \mathrm{~s}, \mathrm{t}=250 \mu \mathrm{s}$, and $650 \mu \mathrm{s}$. The model is section cut along the center of each test plate. 

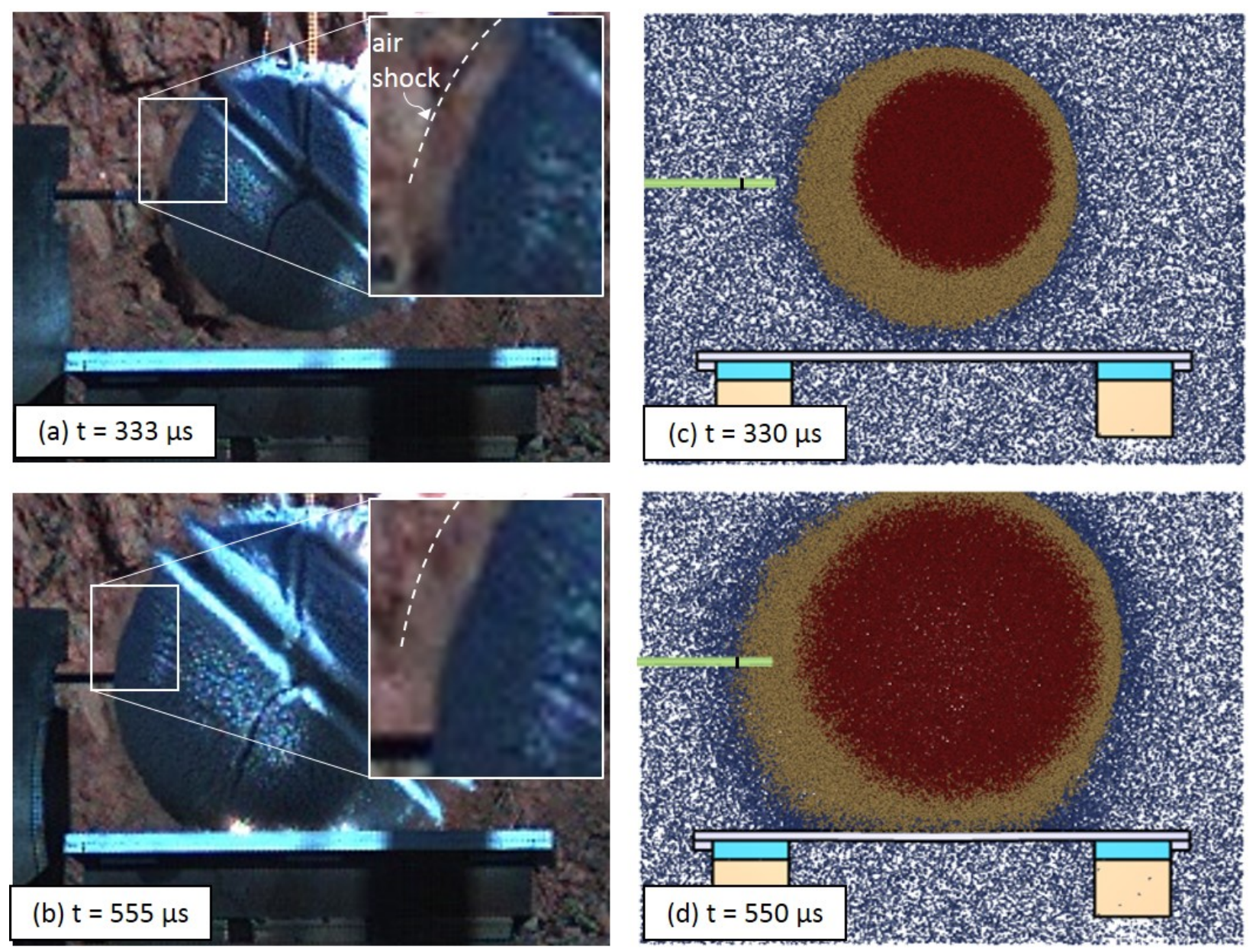

Figure 12. High-speed video images showing the air shock that developed in front of the expanding sand shell for Shot 2 (a) $t=333 \mu$ s and (b) $t=555 \mu$ s after detonation. The insets use a dashed white line to indicate the position of expanding air shock ahead of the particles. Simulation images are shown at approximately equivalent times in (c) at $\mathrm{t}=330 \mu \mathrm{s}$ and in (d) at $\mathrm{t}=550 \mu \mathrm{s}$ after detonation. The blue dots are air particles, and the region of concentration ahead of the expanding particle front corresponds to the shock. The black line on the Kolsky bar in (c) and (d) indicates the $10 \mathrm{~cm}$ length painted region of the Kolsky bar in the high-speed video image in (a). 

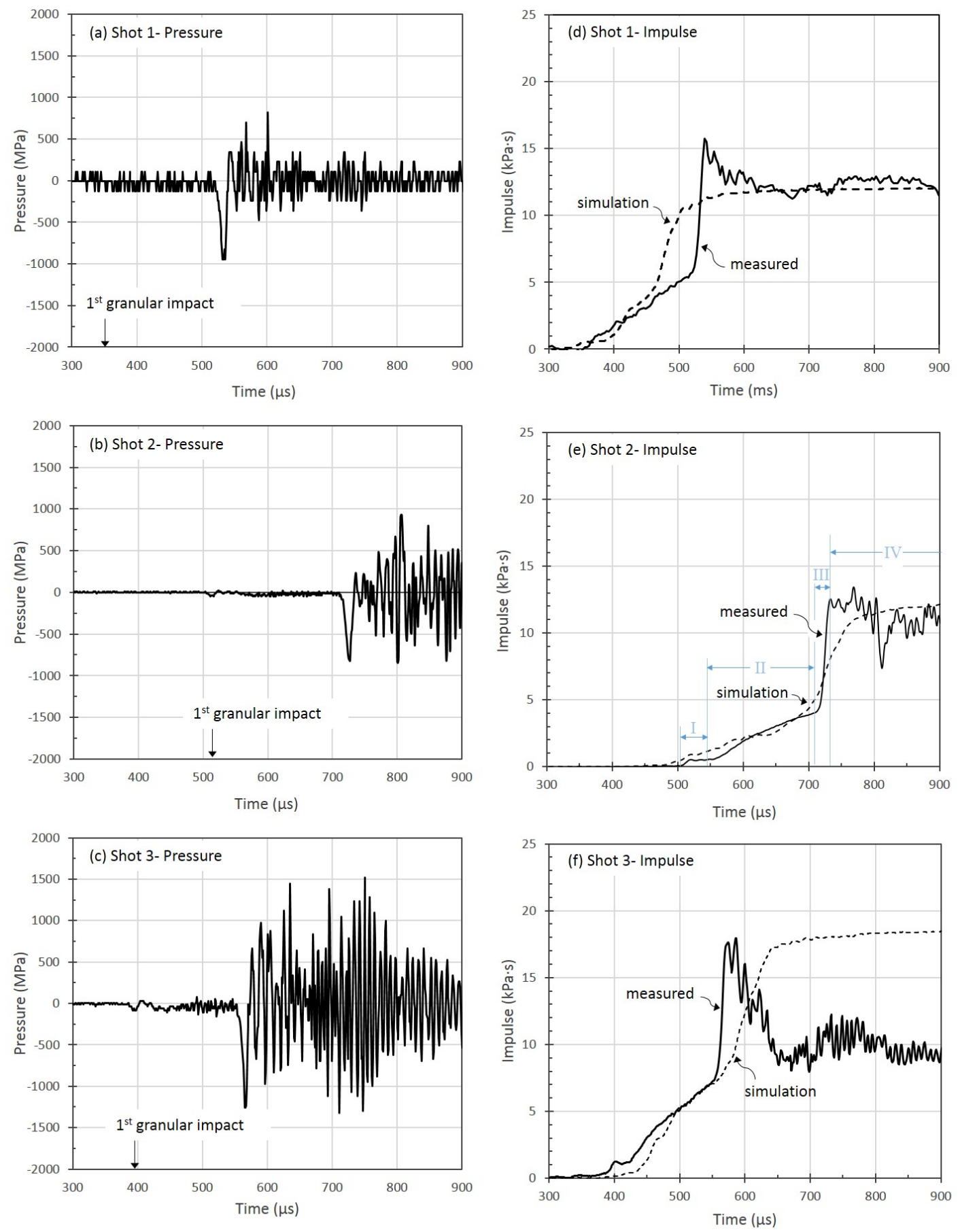

Figure 13. Kolsky bar data for the three glass microsphere tests. The waveforms in (a), (b) and (c) show the pressure measured at the strain gage location for Shots 1, 2 and 3. Figures (d), (e) and (f) show the impulse (measured and simulated) for test Shots 1, 2 and 3. 

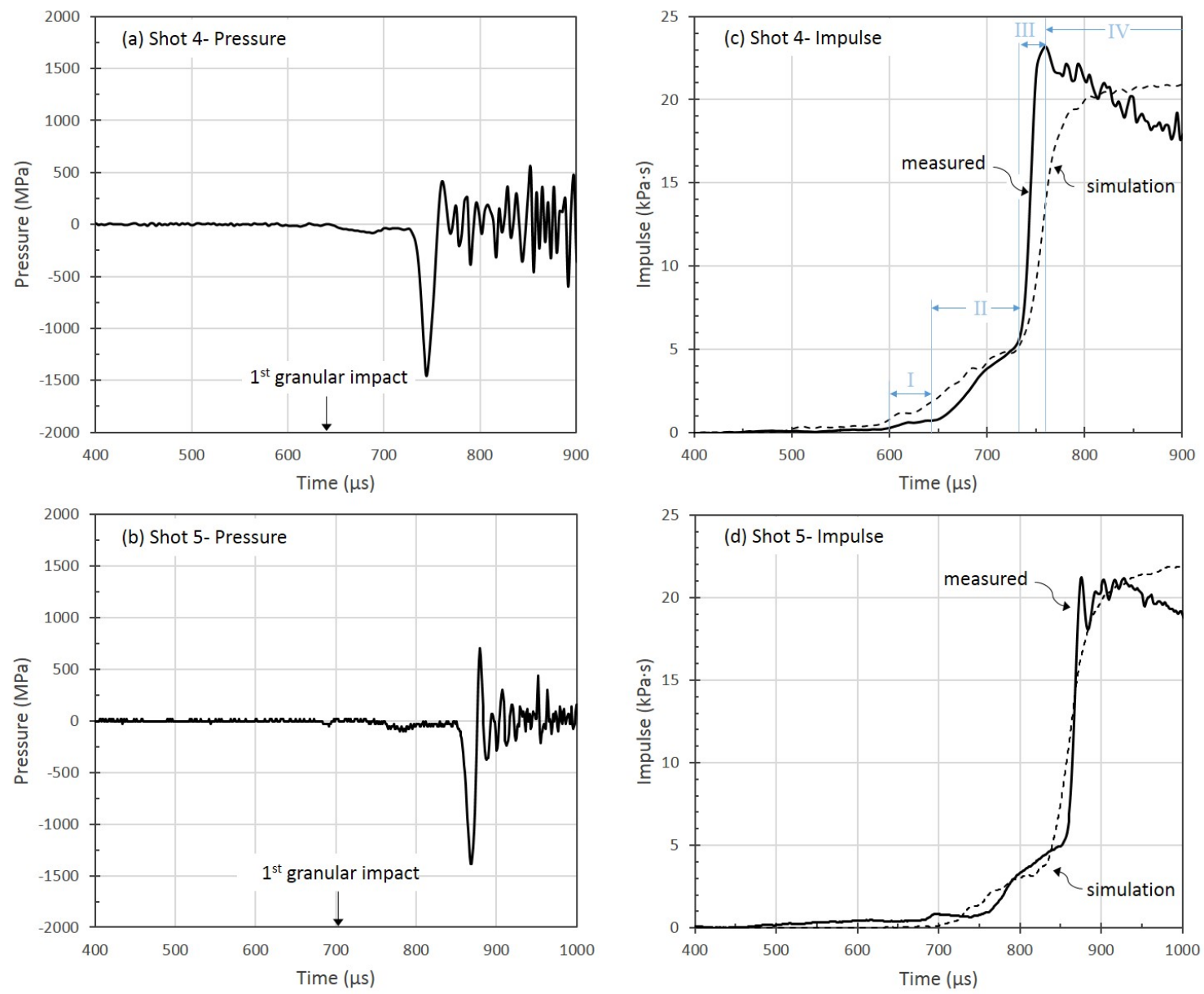

Figure 14. Kolsky bar data for the two zirconia tests (Shots 4 and 5). The waveforms in (a) and (b) show the pressure versus time response measured at the stain gage location for Shots 4 and 5 . The corresponding impulses (measured and simulated) are given in (c) and (d). 

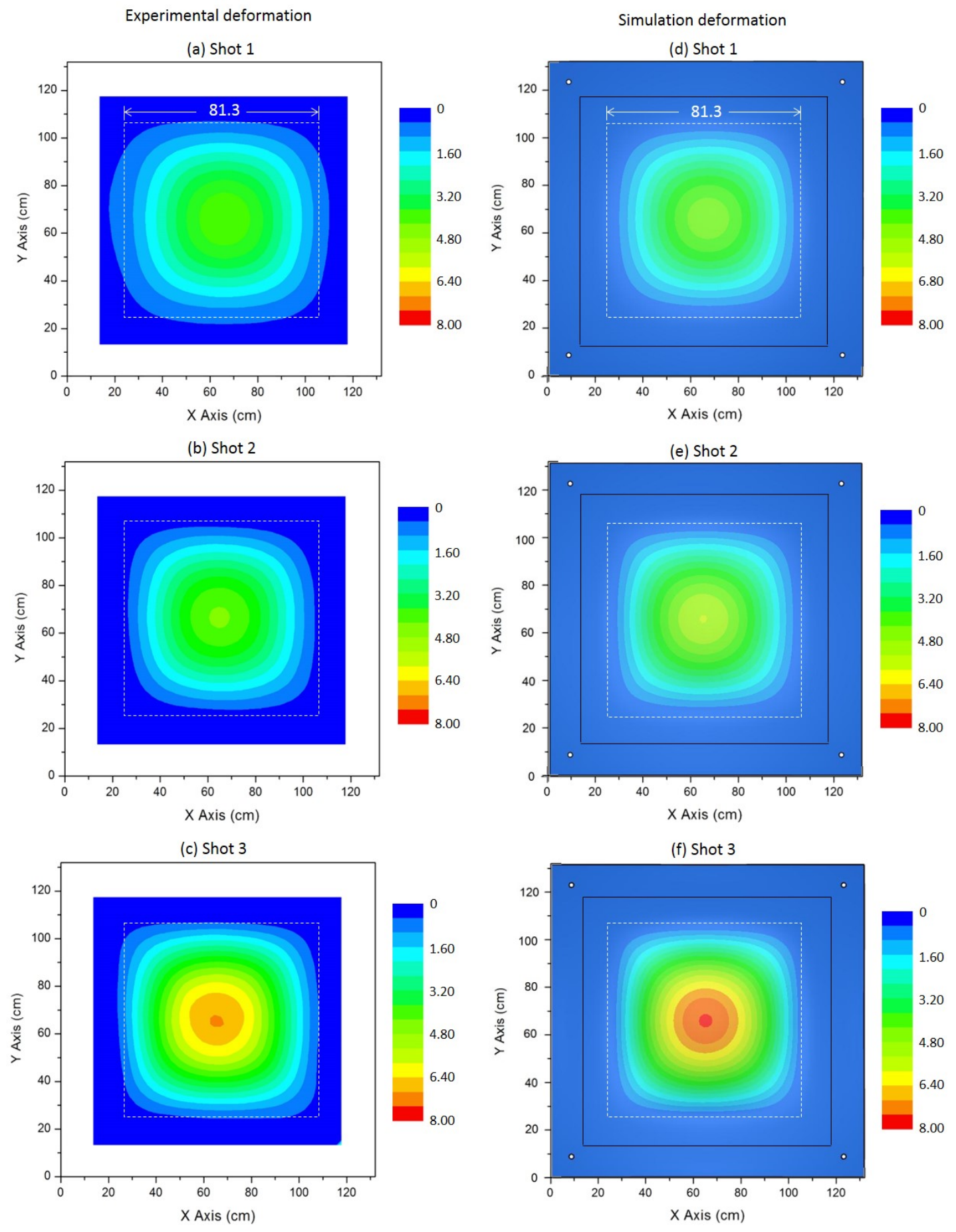

Figure 15. Test plate out of plane displacement contour plots for the glass particle tests (Shots 1, 2 and 3). Experimental profilometry results are shown in (a), (b) and (c). The simulated responses at $\mathrm{t}=20 \mathrm{~ms}$ after plate oscillations had decayed to an approximate steady state displacement are shown in (d), (e) and (f). The white dashed lines indicate the location of the underlying support structure. Within this region, the panels were not back supported. 

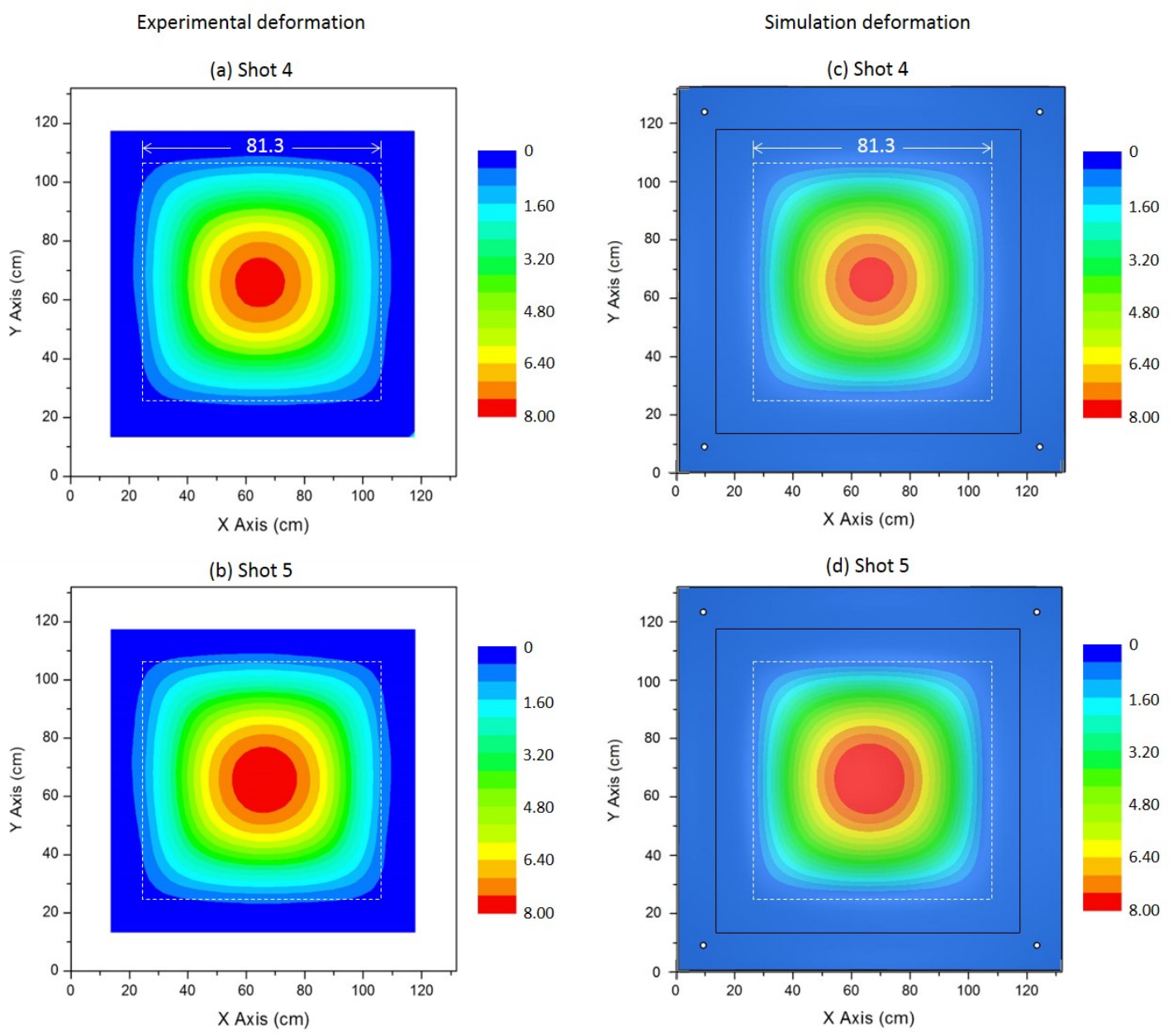

Figure 16. Out of plane displacement contour plots for the zirconia tests (Shots 4 and 5). Experimental results are shown in (a) and (b) while the simulated responses after the plate oscillations had decayed to an approximate steady state $(t=20 \mathrm{~ms})$ are shown in (c) and (d). The white dashed lines indicate the outline of the underlying support structure. 

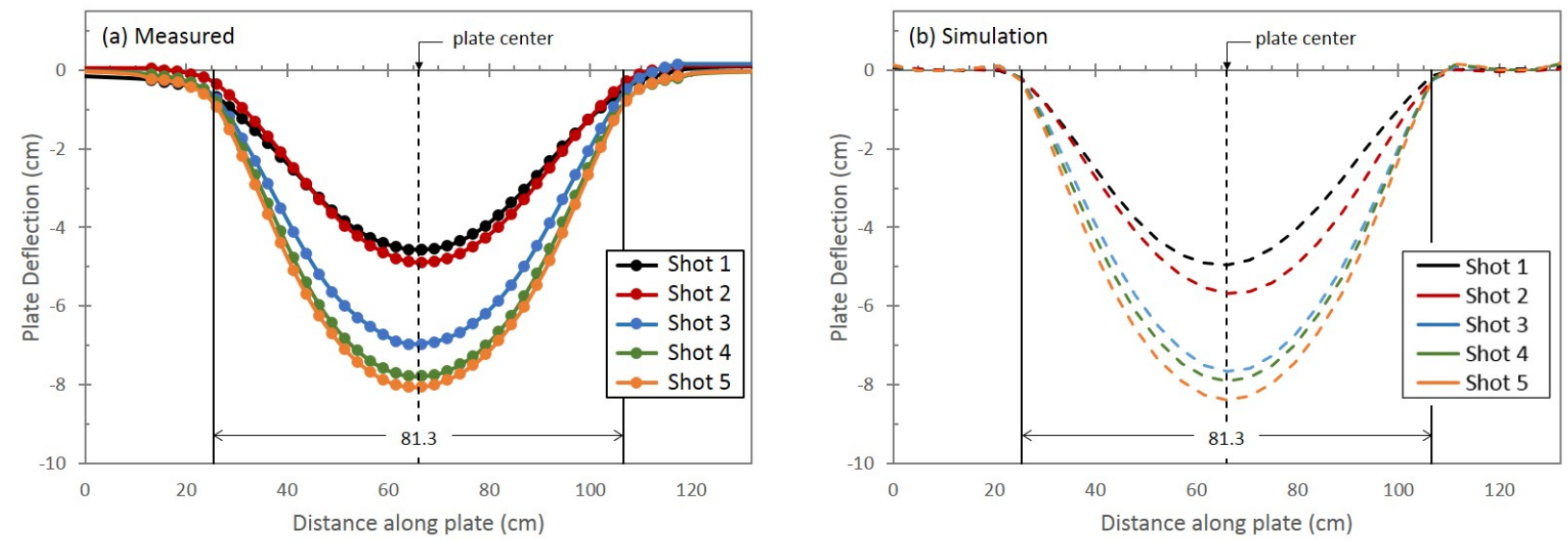

Figure 17. Mid-section out of plane deflection profiles for the five test panels. (a) Measured and (b) simulated results. 


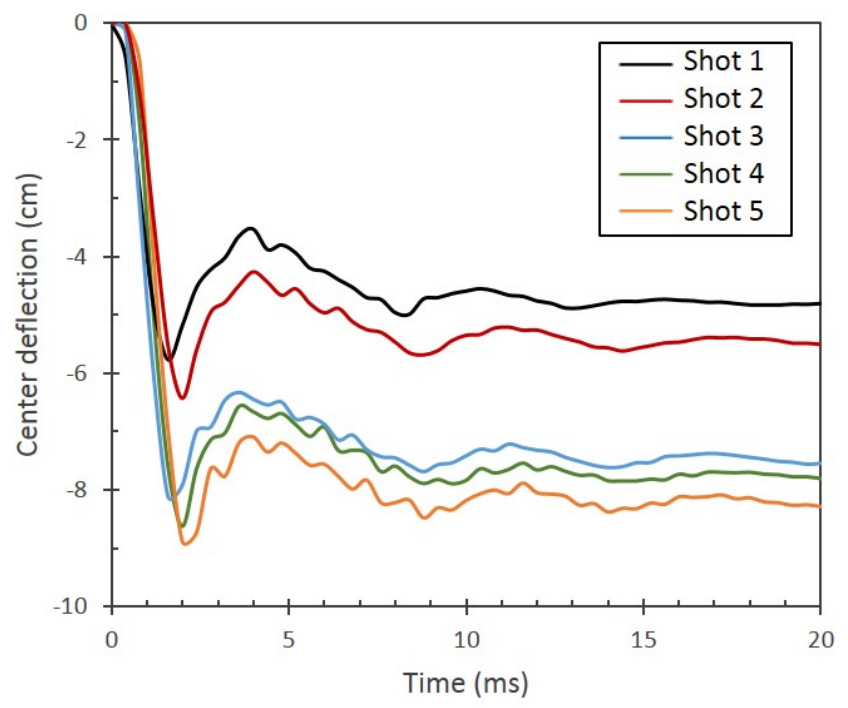

Figure 18. Simulated transient out of plane deflection at the center of the test plates impacted by each test charge. 
(a) Shot 1: $(80,152)$; silica

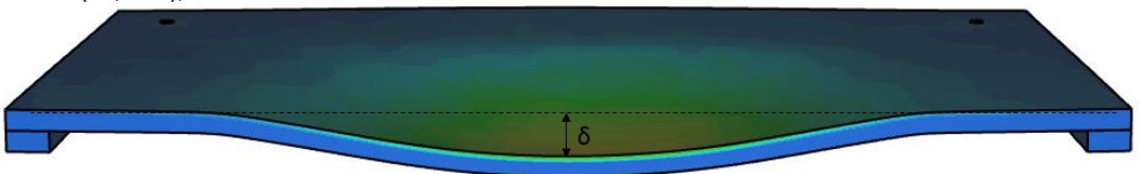

(b) Shot 2: (80, 203); silica

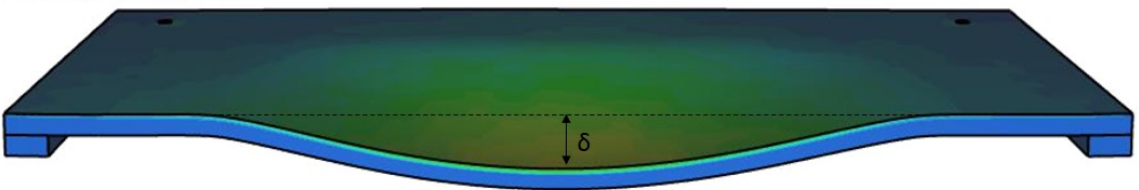

Blast specific impulse (kPa.s)

20

16

(c) Shot 3: $(90,203)$; silica

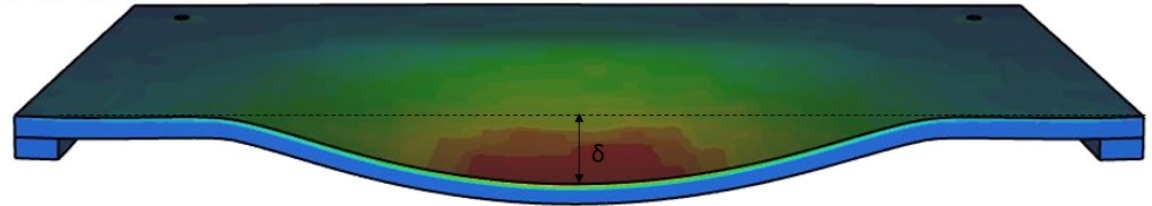

(d) Shot 4: (90, 203); zirconia
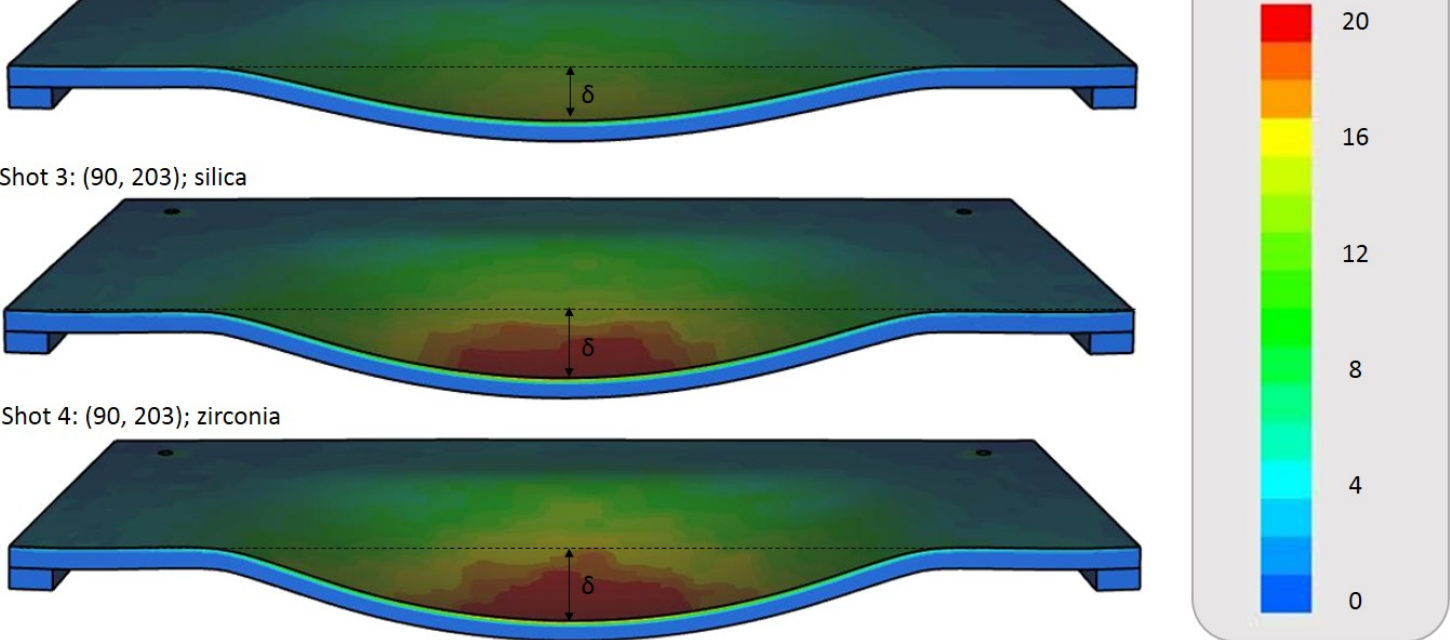

(e) Shot 5: (90, 229); zirconia

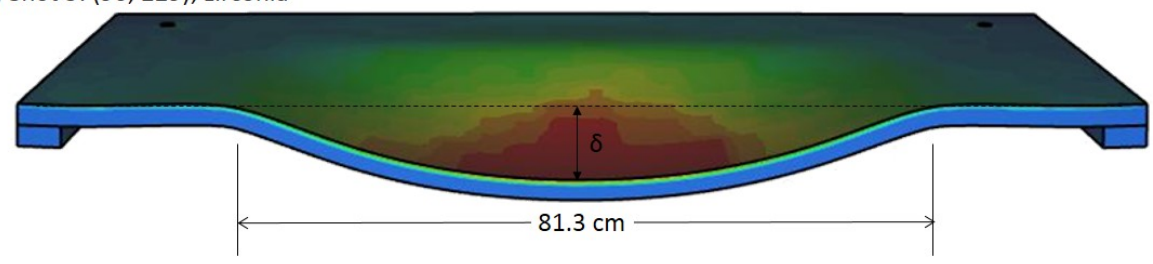

Figure 19. The simulated specific impulse distribution applied to the test plates for the five test charge configurations. The maximum deflection $(\delta)$ is also shown for each test and the $81.3 \mathrm{~cm}$ wide region where no back support of the panels was provided. 

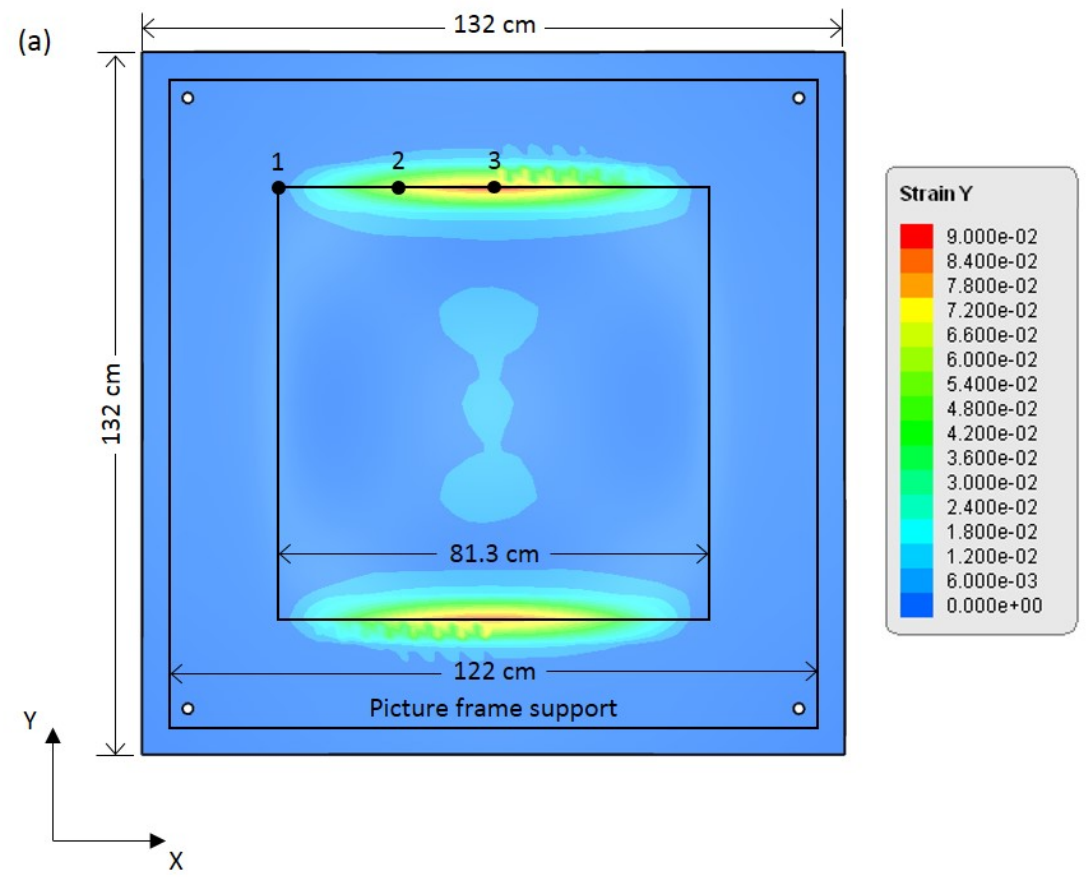

(b)

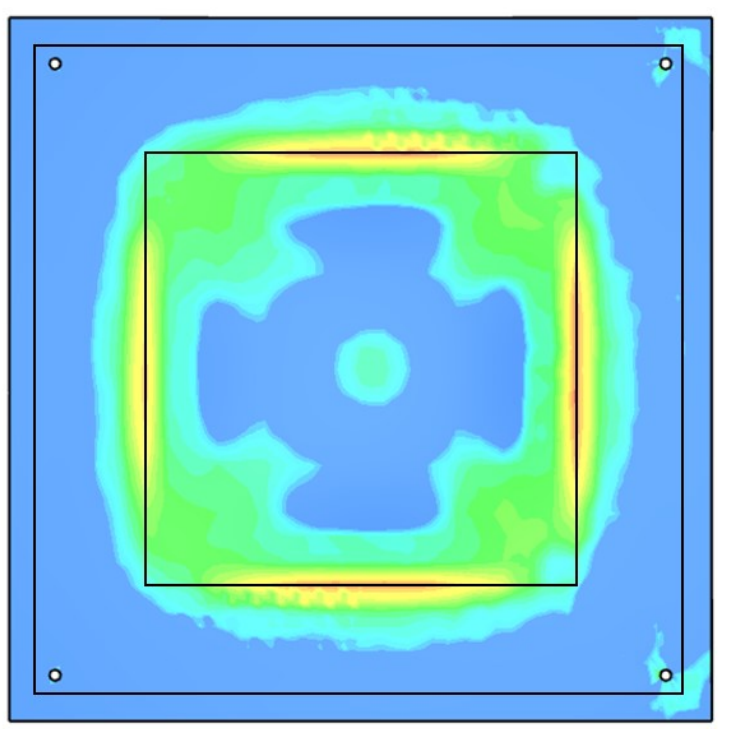

$$
\begin{array}{|}
\text { Effective stress } \\
\hline 6.443 \mathrm{e}+08 \\
6.220 \mathrm{e}+08 \\
5.997 \mathrm{e}+08 \\
5.774 \mathrm{e}+08 \\
5.552 \mathrm{e}+08 \\
5.329 \mathrm{e}+08 \\
5.106 \mathrm{e}+08 \\
4.883 \mathrm{e}+08 \\
4.660 \mathrm{e}+08 \\
4.437 \mathrm{e}+08 \\
4.214 \mathrm{e}+08 \\
3.991 \mathrm{e}+08 \\
3.769 \mathrm{e}+08 \\
3.546 \mathrm{e}+08 \\
3.323 \mathrm{e}+08 \\
3.100 \mathrm{e}+08
\end{array}
$$

Figure 20. (a) The simulated test plate total strain in the y-direction for Shot 3 at $20 \mathrm{~ms}$ after detonation. The samples were edge restrained by the picture frame support (with a span of 122 $\mathrm{cm}$ ). The inner, $81.3 \mathrm{~cm}$ wide center of the panels was not back supported allowing unconstrained out of plane deflection as well as in-plane stretching. The outer $20.35 \mathrm{~cm}$ wide picture frame provided rigid back support of the panels but did not restrain in-plane stretching. Three node locations are indicated where the nodal strain and displacement magnitude were recorded for each test shot. (b) The effective stress for Shot 3 at $1 \mathrm{~ms}$ after detonation showing regions of the plate that that were stressed beyond the yield strength $(310 \mathrm{MPa})$ of the plate material. 


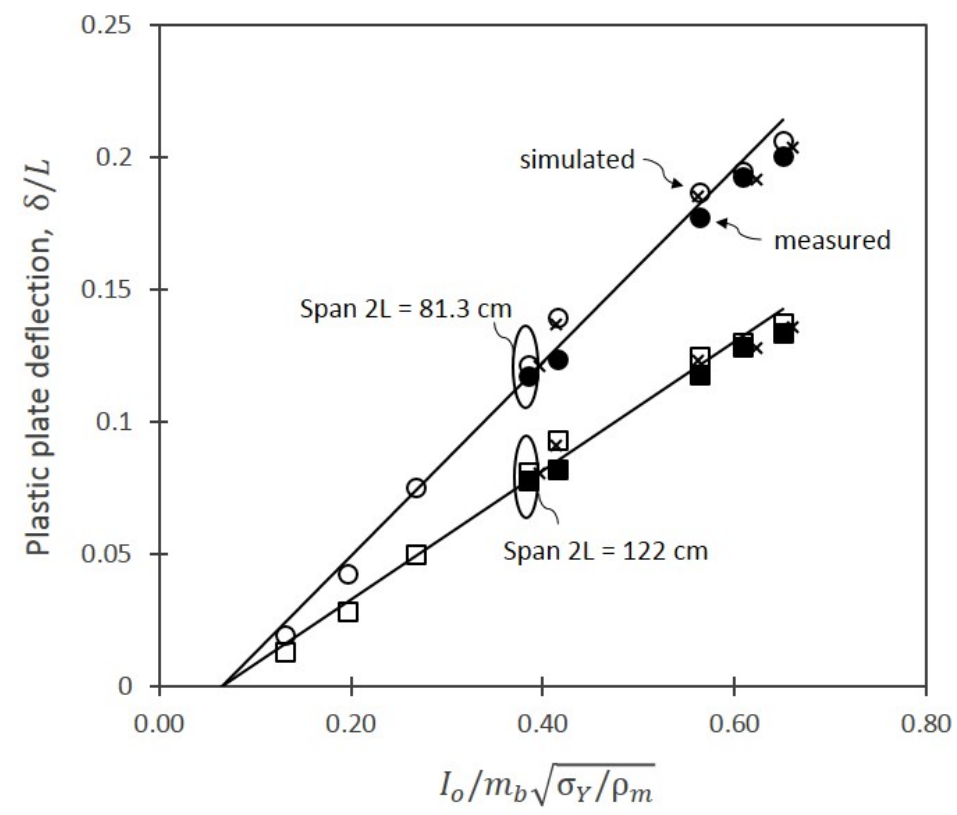

Figure 21. The simulated permanent plate deflection scaled by the half span, L versus dimensionless impulse in which $I_{o}$ corresponded to the maximum simulated specific impulse applied near the test plate centers. Results are shown for the $81.3 \mathrm{~cm}$ wide span where no back support existed (open circles) and the $122 \mathrm{~cm}$ span over which unconstrained in-plane panel stretching was allowed (open squares). The experimentally measured deflections normalized by the two span lengths are also shown (solid circle and solid square data). The $\mathrm{x}$ data points correspond to simulations in which the background air particles were omitted. 
Shot 1: $(80,152)$
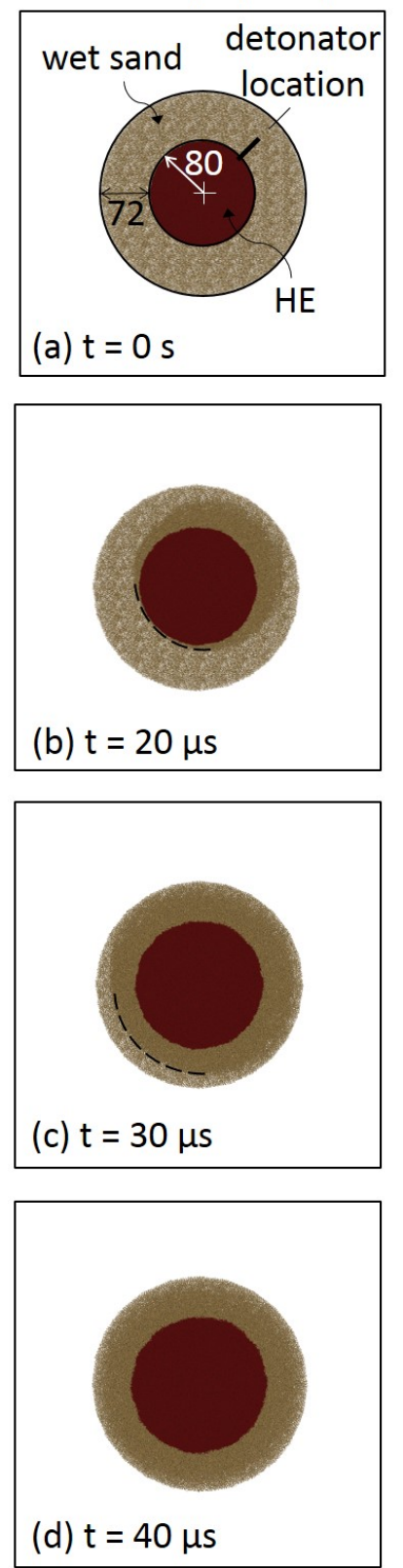

Shot 2: $(80,203)$
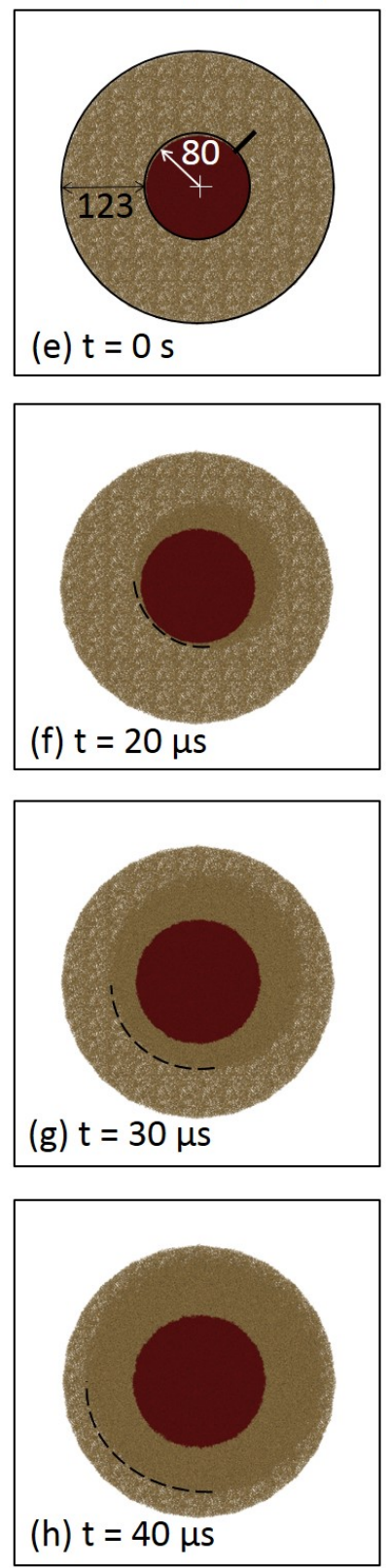

Shot 3: $(80,203)$
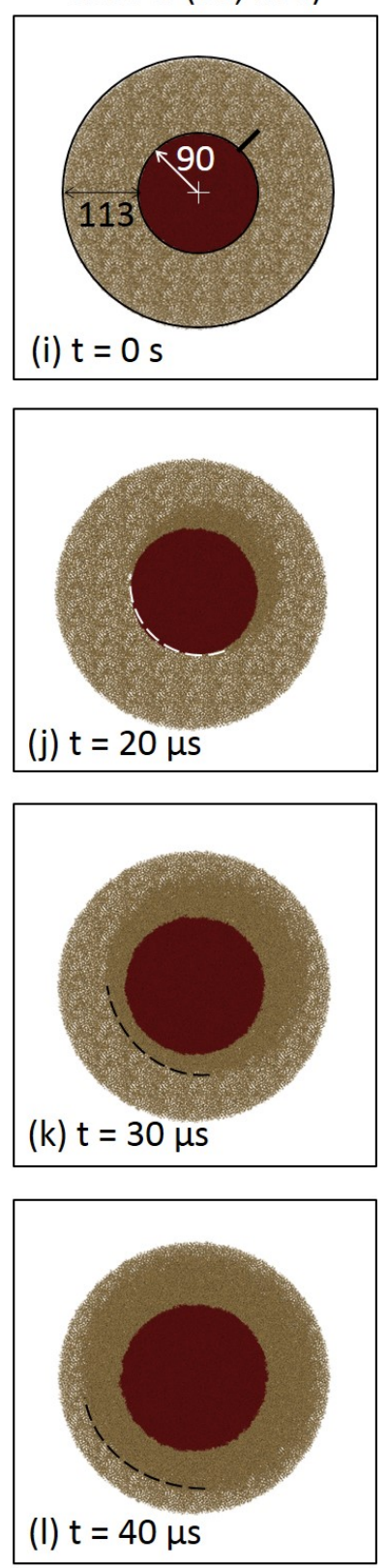

Figure A1. Simulated results showing shock front propagation through the three glass particle charges (Shots 1-3). The dashed white line in (j) shows the approximate location of the detonation front in the explosive while the dashed black lines show the position of the wet sand shock fronts. 
Shot 4: $(90,203)$
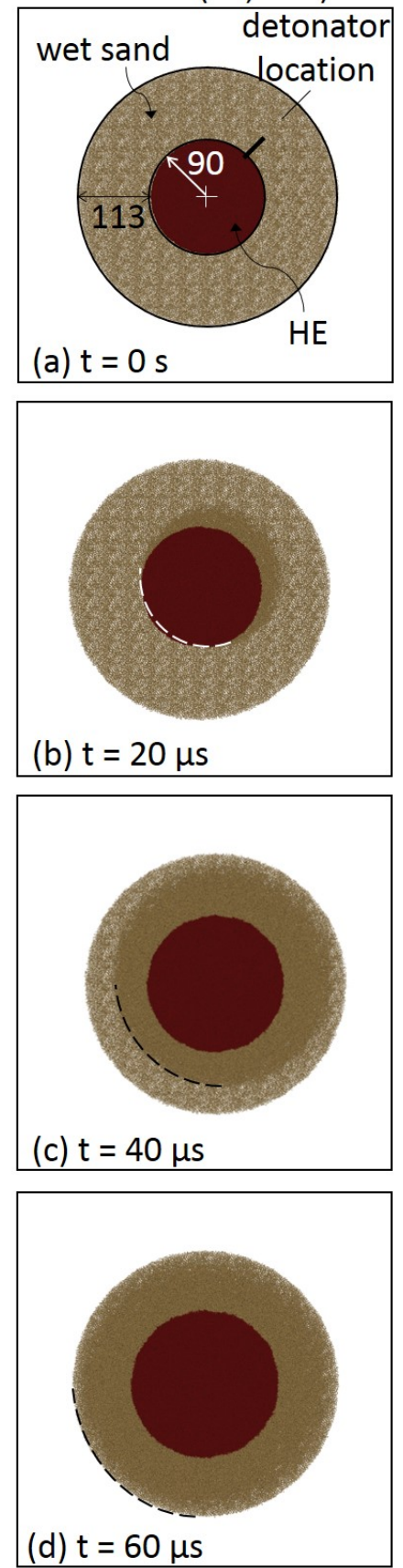

Shot 5: $(90,229)$
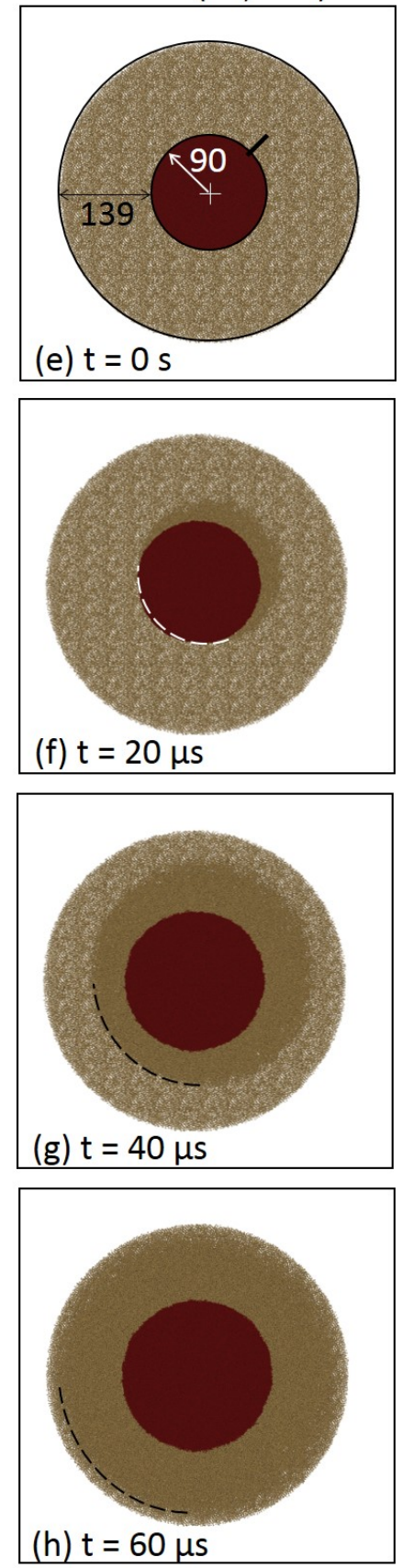

Figure A2. Simulated results showing shock front propagation through the two water saturated zirconia charges (Shots 4 and 5). The dashed white line shows the approximate location of the detonation front in the explosive while the dashed black line shows the shock front locations in the granular media at various times after detonation. 